\title{
TEMIS UV product validation using NILU-UV ground-based measurements in Thessaloniki, Greece
}

\author{
Melina-Maria Zempila ${ }^{1,2}$, Jos H. G. M. van Geffen ${ }^{3}$ Michael Taylor $^{2}$, Ilias Fountoulakis ${ }^{2}$, Maria-Elissavet Koukouli ${ }^{2}$, \\ Michiel van Weele ${ }^{3}$, Ronald J. van der $\mathrm{A}^{3}$, Alkiviadis Bais ${ }^{2}$, Charikleia Meleti ${ }^{2}$, and Dimitrios Balis ${ }^{2}$ \\ ${ }^{1}$ USDA UV-B Monitoring and Research Program, Colorado State University, Fort Collins, Colorado 80523, USA \\ ${ }^{2}$ Laboratory of Atmospheric Physics, Aristotle University of Thessaloniki, P.O. Box 149, 54124, Thessaloniki, Greece \\ ${ }^{3}$ Royal Netherlands Meteorological Institute (KNMI), De Bilt, the Netherlands
}

Correspondence to: Melina-Maria Zempila (melina.zempila@colostate.edu)

Received: 21 December 2016 - Discussion started: 16 February 2017

Revised: 10 May 2017 - Accepted: 11 May 2017 - Published: 16 June 2017

\begin{abstract}
This study aims to cross-validate ground-based and satellite-based models of three photobiological UV effective dose products: the Commission Internationale de l'Éclairage (CIE) erythemal UV, the production of vitamin D in the skin, and DNA damage, using high-temporalresolution surface-based measurements of solar UV spectral irradiances from a synergy of instruments and models. The satellite-based Tropospheric Emission Monitoring Internet Service (TEMIS; version 1.4) UV daily dose data products were evaluated over the period 2009 to 2014 with groundbased data from a Norsk Institutt for Luftforskning (NILU)UV multifilter radiometer located at the northern midlatitude super-site of the Laboratory of Atmospheric Physics, Aristotle University of Thessaloniki (LAP/AUTh), in Greece. For the NILU-UV effective dose rates retrieval algorithm, a neural network $(\mathrm{NN})$ was trained to learn the nonlinear functional relation between NILU-UV irradiances and collocated Brewer-based photobiological effective dose products. Then the algorithm was subjected to sensitivity analysis and validation. The correlation of the NN estimates with target outputs was high $(r=0.988$ to 0.990$)$ and with a very low bias ( 0.000 to 0.011 in absolute units) proving the robustness of the $\mathrm{NN}$ algorithm. For further evaluation of the NILU NN-derived products, retrievals of the vitamin D and DNA-damage effective doses from a collocated Yankee Environmental Systems (YES) UVB-1 pyranometer were used. For cloud-free days, differences in the derived UV doses are better than $2 \%$ for all UV dose products, revealing the reference quality of the ground-based UV doses at Thessa-
\end{abstract}

loniki from the NILU-UV NN retrievals. The TEMIS UV doses used in this study are derived from ozone measurements by the SCIAMACHY/Envisat and GOME2/MetOp-A satellite instruments, over the European domain in combination with SEVIRI/Meteosat-based diurnal cycle of the cloud cover fraction per $0.5^{\circ} \times 0.5^{\circ}$ (lat $\times$ long) grid cells. TEMIS UV doses were found to be $\sim 12.5 \%$ higher than the NILU NN estimates but, despite the presence of a visually apparent seasonal pattern, the $R^{2}$ values were found to be robustly high and equal to $0.92-0.93$ for 1588 all-sky coincidences. These results significantly improve when limiting the dataset to cloud-free days with differences of $0.57 \%$ for the erythemal doses, $1.22 \%$ for the vitamin D doses, and $1.18 \%$ for the DNA-damage doses, with standard deviations of the order of $11-13 \%$. The improvement of the comparative statistics under cloud-free cases further testifies to the importance of the appropriate consideration of the contribution of clouds in the UV radiation reaching the Earth's surface. For the urban area of Thessaloniki, with highly variable aerosol, the weakness of the implicit aerosol information introduced to the TEMIS UV dose algorithm was revealed by comparison of the datasets to aerosol optical depths at $340 \mathrm{~nm}$ as reported by a collocated CIMEL sun photometer, operating in Thessaloniki at LAP/AUTh as part of the NASA Aerosol Robotic Network. 


\section{Introduction}

During the last few decades, the danger of overexposure to solar UV radiation has been well analyzed and a causal link has been established to skin diseases and cancer since the mutation of DNA can be triggered by UV-B doses (Xiang et al., 2014; Parkin et al., 2011; Berwick et al., 2005; Setlow, 1974; among others). On the other hand, the cutaneous production of vitamin D, a "vitamin" that is proven to be essential for human health, is also activated by spectral UV radiation. Hence, accurate knowledge of "safe" UV doses for humans is paramount in order to balance the harmful and beneficial effects of UV exposure (e.g., McKenzie et al., 2009; Webb et al., 1988; MacLaughlin et al., 1982). Of particular relevance is the Commission Internationale de l'Éclairage (CIE) action spectrum as a model for the susceptibility of skin to sunburn (erythema) (McKinlay and Diffey, 1987). As a result of advances in the fields of photobiology and groundbased measurements of UV using different types of instrumentation, a variety of methods now exist to obtain erythemal, vitamin D, and DNA-damage dose rates (Kazantzidis et al., 2009; Webb and Engelsen, 2006; Pope et al., 2008; Engelsen et al., 2005; Samanek et al., 2006).

In parallel, space technology has been making huge steps forward to monitor the Earth's surface and atmosphere at higher spatial and temporal resolution and erythemal, vitamin D, and DNA-damage dose rates and doses can now be retrieved globally from solar backscattered radiation observations from different satellite sensors. Subsequently, long, reliable, and high-temporal-resolution ground-based estimates of surface photobiological effective dose quantities are of high importance in order to validate and characterize the satellite-derived UV products. Ozone layer depletion and recovery in times of climate change reinforce the need for establishing global long-term and quality-assured climate data records of the incident solar UV daily doses at the surface.

In this study, photobiological UV daily doses retrieved from ground-based measurements using empirical models and satellite estimates are cross-validated to assess their accuracy and potential utility.

\section{TEMIS satellite-based UV data products}

\subsection{Operational services}

The Tropospheric Emission Monitoring Internet Service (TEMIS) was established in 2001 at the Royal Netherlands Meteorological Institute (KNMI) as part of a project from the European Space Agency (ESA), and the service has been maintained since. The TEMIS UV data product services started in 2003 and are available through the web portal at http://www.temis.nl/uvradiation/. The UV products, currently version 1.4 , are produced in near-real time on a latitude $\times$ longitude grid of $0.5^{\circ} \times 0.5^{\circ}$ and consist of datasets, maps, and time series. The products are calculated using operational satellite data streams of the global ozone distribution and, over Europe, the diurnal variation in cloud cover fraction.

The TEMIS UV data products essentially exploit the empirically based parametrization by Allaart et al. (2004) of the amount of $U V$ radiation incident at the surface in $\mathrm{W} \mathrm{m}^{-2}$, as a function of the total ozone column and the solar zenith angle at a given local solar time, taking into account an appropriate action spectrum, i.e., the wavelength-dependent response to UV radiation of health effects or otherwise.

Since the initiation of the TEMIS UV services, maintenance and updates have been implemented following, for example, changes in the operational assimilated global ozone distribution (Eskes et al., 2003), which were based on the SCIAMACHY instrument aboard ENVISAT (Bovensmann et al., 1999) up to April 2012, and later on GOME-2 aboard MetOp-A (Hassinen et al., 2016). Recently, the global ozone Multi-Sensor Reanalysis version 2 (MSR-2) by van der A et al. (2015) has been used to create a reanalysis of the global clear-sky UV index for a longer historical period (from November 1978 to December 2012).

Cloud attenuation over Europe is prescribed using the near-real time cloud mask product (Derrien and Le Gléau, 2005) provided by the EUMETSAT Nowcasting Satellite Application Facility (NWC-SAF), which has been received, processed, and archived at KNMI since July 2005. The operational cloud cover dataset has been based on the different SEVIRI instruments that have been operational aboard the Meteosat Second Generation (MSG) satellites from January 2004 onwards using the Meteosat 8, 9, and 10 platforms. The effect of grid cell average surface elevation, though not the actual 3-D topography, on surface UV is taken into account in the calculations. Changes in surface albedo are prescribed using a monthly climatology of surface reflectivity (Herman and Celarier, 1997). The effects of aerosols are included implicitly in the parameterization but do not vary over time (Badosa and van Weele, 2002).

\subsection{Products and algorithms}

TEMIS provides two types of surface UV products: (i) the clear-sky erythemal UV index and (ii) the daily UV dose (daily integral) related to different health effects. The erythemal UV index (UVI) is determined using the action spectrum adopted by the International Commission on Illumination (CIE) for erythema or reddening of the skin due to sunburn. In the current v1.4 TEMIS service, the UVI is based on the CIE action spectrum described by McKinlay and Diffey (1987). Webb et al. (2011) describe an improved version of that action spectrum adopted by CIE in 1998. The effect of this improvement on the UVI values is small, well below $1 \%$ except for high solar zenith angle situations (Webb et al., 2011). The improved CIE erythemal action spectrum will be 

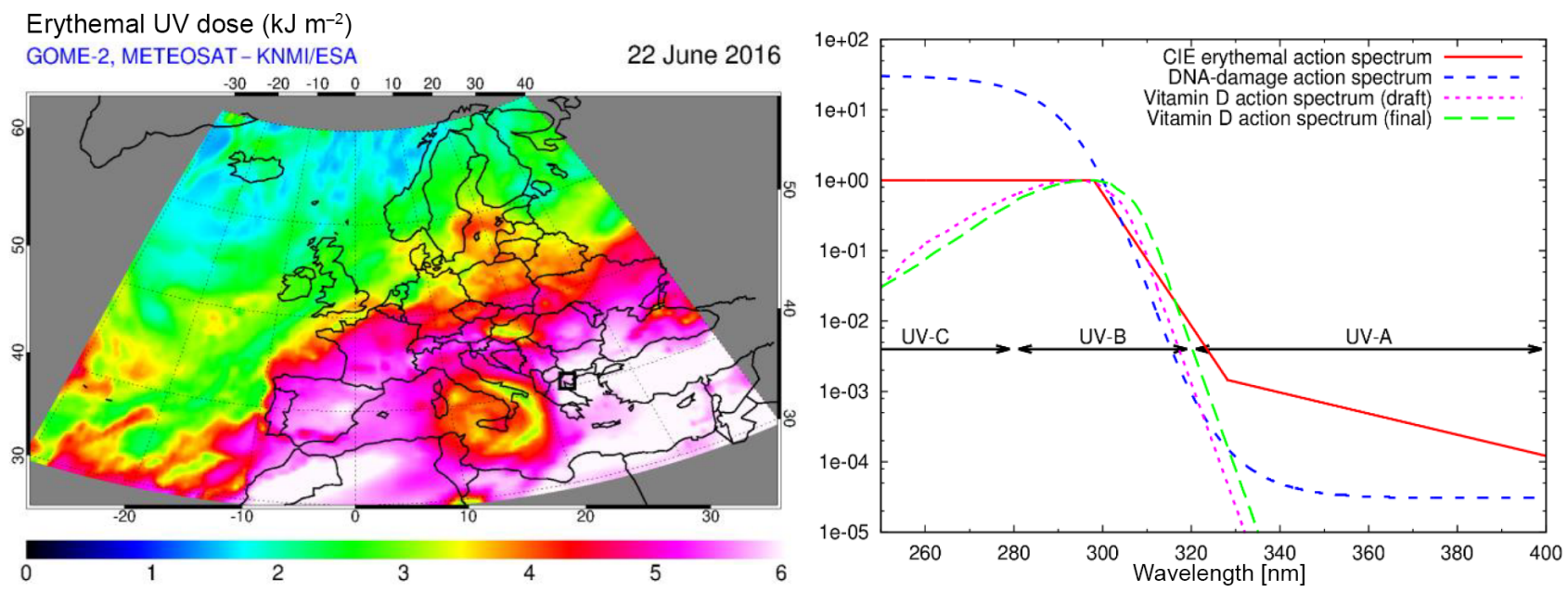

Figure 1. Left panel: erythemal UV dose over Europe on 22 June 2016. Thessaloniki, indicated by a black square, had an almost cloud-free day with an erythemal UV dose of $5.77 \mathrm{~kJ} \mathrm{~m}^{-2}$ and an erythemal UV index of 10.1. Right panel: action spectra of erythema (red solid line), generalized DNA damage (blue dashed line), and production of vitamin D (magenta dotted line: draft version as used within TEMIS (Holick et al., 2005); green dashed line: final version as adopted by the CIE (Bouillon et al., 2006)).

included in the forthcoming upgrade (v2.0) of the TEMIS service.

Following international agreements, the UVI represents the amount of UV radiation at local solar noon, i.e., when the Sun is highest in the sky, under clear-sky conditions. The UVI is usually given as a dimensionless index, where 1 unit equals $25 \mathrm{~mW} \mathrm{~m}^{-2}$. Using the operational meteorological data streams (temperature, pressure, winds) which are included in the ozone data assimilation (Eskes et al., 2003), the UVI is available in forecast mode and TEMIS provides forecasts of both the global ozone field and UVI for today and the coming 8 days.

The daily UV dose (UVD) is the total amount of UV radiation, usually given in $\mathrm{kJ} \mathrm{m}^{-2}$, integrated between sunrise and sunset, accounting for the variation in the solar zenith angle (SZA) and cloud cover fraction (in TEMIS version 1.4); this is available over Europe only) during the day (see Fig. 1, left). The UV dose is calculated for three action spectra (see Fig. 1, right): the erythemal UV dose (UVD-CIE) based on the CIE erythemal action spectrum (McKinlay and Diffey, 1987), identical to the one used for the UVI-CIE, the generalized DNA-damage UV dose (UVD-DNA) based on the action spectrum determined by Setlow (1974) and normalized at $300 \mathrm{~nm}$ based on Bernhard and Seckmeyer (1997), and the vitamin D UV dose (UVD-VitD) based on the action spectrum for the production of previtamin D3 in the human skin (Holick et al., 2005).

Note that the 2005 (draft) version by Holick et al. (2005) used for UVD-VitD within TEMIS differs from the CIEadopted vitamin D action spectrum (Bouillon et al., 2006) (see Fig. 1, right). The difference, which includes a wavelength shift of $3 \mathrm{~nm}$ (the applied action spectrum peaks at $295 \mathrm{~nm}$ and not at $298 \mathrm{~nm}$ as proposed by CIE), would in- crease the TEMIS data by a factor of about 2.2 (2.1 in summer, 2.3 in winter) when using the CIE vitamin D action spectrum - an important change that will be implemented in a forthcoming update (v2.0) of the TEMIS UV operational data streams.

For each action spectrum, a parametrization is applied following Allaart et al. (2004) for the UV solar irradiance as a function of SZA $(t)$ and total ozone column providing a first guess of the UV irradiance weighted with a specific action spectrum $\left(\mathrm{UVI}^{\prime}\right)$, at time $t$ using the global assimilated ozone field at local solar noon $(t=12 \mathrm{~h})$.

The final UVI $(t)$, which can be seen as the UV index at time $t$ (i.e., with a time-dependent SZA), is then calculated from $\mathrm{UVI}^{\prime}(t)$ by applying a set of correction factors:

$$
\mathrm{UVI}(t)=\mathrm{UVI}^{\prime}(t) \cdot f_{\mathrm{D}} \cdot f_{\mathrm{C}} \cdot f_{\mathrm{H}} \cdot f_{\mathrm{A}} \quad\left(\mathrm{W} \mathrm{m}^{-2}\right),
$$

where $f_{\mathrm{D}}$ is the correction for the day-to-day variation in the Sun-Earth distance, $f_{\mathrm{C}}$ the correction for the attenuation due to clouds (in the case of clear-sky conditions: $f_{\mathrm{C}}=1$ ), $f_{\mathrm{H}}$ the correction for the surface elevation, and $f_{\mathrm{A}}$ the correction for the ground albedo.

The UVI index at local solar noon, UVI $(t=12 \mathrm{~h})$, follows directly from Eq. (1), i.e., using SZA $(t=12 \mathrm{~h})$, after division by $25\left(\mathrm{~mW} \mathrm{~m}^{-2}\right)$. The TEMIS products' uncertainty can currently only be estimated from the errors reported in the ozone total amount; thus, it reflects the lower boundary of the errors seen in the UV doses. Based on this fact, TEMIS products include an uncertainty of 2-3\% in the daily doses. The UVD products, in $\mathrm{kJ} \mathrm{m}^{-2}$, are determined from a $10 \mathrm{~min}$ step integration of UVI $(t)$, with a time-dependent SZA, over time $t$ between sunrise and sunset, which are assumed to lie symmetrically around local solar noon. 
For the calculation of $f_{\mathrm{C}}$ the NWC-SAF cloud mask (Derrien and Le Gléau, 2005) is converted to a cloud fraction $\left(C_{\mathrm{f}}\right)$ by counting the clear vs. cloudy instances per UV grid cell of $0.5^{\circ} \times 0.5^{\circ}$ (latitude $\times$ longitude) .

The cloud correction factor in Eq. (1) is then given by

$$
f_{\mathrm{C}}= \begin{cases}1.0, & C_{\mathrm{f}}<0.02 \\ 0.9651-0.2555 \cdot C_{\mathrm{f}}, & 0.02 \leq C_{\mathrm{f}} \leq 0.98, \\ 0.5, & C_{\mathrm{f}}>0.98\end{cases}
$$

a relationship that has been determined from the effect of clouds on surface UV at the location of KNMI at De Bilt in the Netherlands (van Geffen et al., 2004; van Weele et al., 2005). For the calculation of $f_{\mathrm{H}}$ a $5 \%$ increase of the incident UV irradiance per $\mathrm{km}$ surface elevation above sea level is assumed:

$f_{\mathrm{H}}=1+0.05 \cdot H$,

where the surface elevation $H$ (in $\mathrm{km}$ ) is determined from the GTOPO30 database (https://lta.cr.usgs.gov/GTOPO30/), resampled to the $0.5^{\circ} \times 0.5^{\circ} \mathrm{UV}$ grid. For the calculation of $f_{\mathrm{A}}$ the following function of ground albedo $\left(A_{\mathrm{g}}\right)$ is applied, taking into account multiple reflections between the surface and the overlying atmosphere:

$f_{\mathrm{A}}=\frac{1-0.25 \cdot 0.09}{1-0.25 \cdot A_{\mathrm{g}}}$.

The function derives from the series $1+x y+(x y)^{2}+\ldots=$ $1 /(1-x y)$, where $x=0.25$ is the UV albedo of the overlying atmosphere for upward-reflected UV radiation and $y=A_{\mathrm{g}}$. Since the Allaart et al. (2004) UV index parameterization is empirically based on UV data collected at De Bilt and Paramaribo, the $A_{\mathrm{g}}$ at these (urban) sites - with a 12-month average value of 0.09 - is used as a normalization factor for the calculation of $f_{\mathrm{A}}$. The data for $A_{\mathrm{g}}$ at each UV grid cell are taken at $335 \mathrm{~nm}$ from the monthly TOMS/GOME climatology, which uses the spectral dependency of the GOME database (Koelemeijer et al., 2003) but with a scaling to match the TOMS 340/380 nm database (Herman and Celarier, 1997; Boersma et al., 2004).

Note that there is no explicit correction in Eq. (1) for the variable presence of aerosols in the TEMIS UV data products. However, the Allaart et al. (2004) empirically based parametrization includes an implicit aerosol correction due to the average aerosol load over these two urban sites: an aerosol optical depth (AOD) at $368 \mathrm{~nm}$ of 0.3 and an aerosol single-scattering albedo (SSA) of 0.9 (Badosa and van Weele, 2002). For situations where the real aerosol load is lower (higher) than the assumed load, the UV data products will underestimate (overestimate) the UV index and UV dose. With potential future near-real time availability of aerosol optical parameters at a global scale, the correction factors derived by Badosa and van Weele (2002) could be applied within future updates of the TEMIS UV services.

\section{Ground-based data products}

\subsection{Instruments at Thessaloniki}

The calculation of the photobiological doses over Thessaloniki $\left(40.63^{\circ} \mathrm{E}, 22.96^{\circ} \mathrm{N}\right)$ are based on measurements taken by three different types of instruments in continuous operation at the Laboratory of Atmospheric Physics of the Aristotle University of Thessaloniki (LAP/AUTh: http://lap. physics.auth.gr).

Firstly, a Brewer MKIII spectrophotometer with serial number \#086 (B086) is equipped with a double monochromator and measures the UV solar irradiance spectrum $(286.5-363 \mathrm{~nm})$ with a wavelength step of $0.5 \mathrm{~nm}$. Every scan lasts $7 \mathrm{~min}$, while the use of a triangular-like slit results in a bandwidth of $0.55 \mathrm{~nm}$ full width at half maximum (FWHM). The spectra used in this study have recently been subjected to quality control and re-evaluation (Fountoulakis et al., 2016a), after which the remaining $1 \sigma$ uncertainty is estimated to be $5 \%$ (Garane et al., 2006) for wavelengths longer than $305 \mathrm{~nm}$ and for SZAs smaller than $80^{\circ}$. For lower wavelengths and larger SZA the uncertainty is larger as a consequence of the photon noise that dominates due to the low recorded signal (Fountoulakis et al., 2016b). The simpler, single-monochromator Brewer instrument with serial number \#005 (B005) has been operational in Thessaloniki since 1982 and has been providing continuous, well-calibrated, and documented total ozone column measurements (Bais et al., 1985; Meleti et al., 2012; Zerefos, 1984).

Secondly, a Norsk Institutt for Luftforskning (NILU)-UV multi-filter radiometer has been fully operational in Thessaloniki since 2005 and forms part of the UVNET network of NILU-UV radiometers (http://www.uvnet.gr, Kazantzidis et al., 2006). The NILU-UV with serial number 04103 (NILU103) provides 1 min measurements in five UV channels with nominal central wavelength at $302,312,320,340$, and $380 \mathrm{~nm}$ and a FWHM of $10 \mathrm{~nm}$, while its sixth channel measures the photosynthetically active radiation (PAR) and is used here to determine cloud-free cases based on the cloud detection algorithm proposed by Zempila et al. (2016a). Although the B086 measures the UV spectrum with high spectral resolution, the time frequency of the scans usually varies from 20 to $40 \mathrm{~min}$. Nevertheless, Brewer spectrophotometers are a very powerful means for calibrating other UV measuring instruments that provide higher temporal resolution measurements.

Specifically, for the calibration of NILU103 raw data, cloud-free response-weighted irradiances were derived from B086's measured spectra. Since B086 scans the UV solar spectrum within approximately $7 \mathrm{~min}$, the time period needed to scan the spectral range of each NILU103's channel spectral response is approximately $3 \mathrm{~min}$. The coincidences of NILU103's raw data to B086's weighted spectra were performed based on the time that B086 measured the wavelength 
at which each channel peaks. Subsequently, the time difference that can be introduced between the two datasets is normally less than $\pm 1 \mathrm{~min}$. To account for this time window, the mean values of three consecutive NILU103 measurements were analyzed, with the central one chosen to be the closest to B086's time scan of the peak wavelength of each channel. Then, NILU103's data were corrected for possible drifts in time via a time-dependent smoothing spline fit. Furthermore, the drifts of the channels were monitored through monthly lamp measurements. Both methods resulted in the same patterns for the drifted channels. After correcting for time drifts, a time-independent absolute calibration factor was derived through scatter plots based on linear regression through origin. To evaluate the validity of the calibration procedures, the NILU103 calibrated data were compared once again with B086 response-weighted irradiances and the time series were checked for time drifts and SZA dependence. By calibrating the NILU103 measurements with the B086 coincident response-weighted irradiances, we estimate that the uncertainties of the NILU103 measurements used in this study are $5.6 \%$ (Zempila et al., 2016b).

Thirdly, a Yankee Environmental Systems (YES) UVB1 radiometer operating also in Thessaloniki, provides $1 \mathrm{~min}$ erythemal dose measurements with a spectral response very similar to the erythemal action spectrum (McKinlay and Diffey, 1987). Using model simulations with the libRadtran radiative transfer (Emde et al., 2016) proper weighting factors are calculated with respect to SZA and the total ozone column (TOC). These factors are used to transform the UVB-1 measurements into erythemal irradiance (Lantz et al., 1999). A similar transformation is applied for the vitamin D and DNA-damage weighted irradiances (see Sect. 3.2.3). In addition, the Brewer measurements have been used to correct the UVB-1 observations for the degradation of its absolute spectral response and for sudden changes in the behavior of the instrument. Thus, the datasets from the UVB-1 and the NILU-UV radiometers are not completely independent since the Brewer instrument was used for the calibration of both instruments.

In addition, at Thessaloniki, a CE318-N sun-sky photometer, also known as a CIMEL, provides continuously atmospheric observations through the NASA Aerosol Robotic Network (AERONET) (Balis et al., 2010). The CIMEL provides aerosol optical depth at the UV wavelength of $340 \mathrm{~nm}$, amongst other aerosol properties, which is used to investigate the effects of aerosol variability at Thessaloniki on comparisons with the satellite-derived UV products.

\subsection{Products and algorithms}

\subsubsection{Effective UV doses from the Brewer spectrophotometer}

The B086 spectra were processed by the SHICrivm algorithm and extended to $400 \mathrm{~nm}$ (Slaper et al., 1995). The ex- tended spectra were validated with a collocated EKO UV-A instrument (Zempila et al., 2016b) and weighted with the action spectra for (i) the erythemal dose (McKinlay and Diffey, 1987), (ii) the formation of vitamin $D$ in the human skin (Holick et al., 2005), and (iii) DNA damage (Setlow, 1974). The corresponding effective doses have been calculated by integrating the weighted spectra over the nominal wavelength range, while the time of measured doses was matched to the time that B086 scanned the wavelength where the highest sensitivity of each action spectrum is found. Since DNAdamage action spectrum peaks at the lower measured wavelengths, the correspondent time was chosen to be the starting point of the scan. It appears that in most cases the three doses have time differences less than $1 \mathrm{~min}$. The $1 \sigma$ uncertainty of the derived effective doses for the erythema and the vitamin $\mathrm{D}$ is estimated to be $5 \%$ since the contribution of photons with wavelengths shorter than $305 \mathrm{~nm}$ (where the signal may be very low) is small. However, the uncertainty in the calculated effective dose for the DNA damage is larger at SZA greater than $60^{\circ}$ because of the important contribution of shorter wavelengths (very low signal levels) and may reach $20 \%$ for SZAs near $80^{\circ}$ in overcast conditions. The B086 provides measurements with a time frequency of 20 to $40 \mathrm{~min}$, but atmospheric circumstances can change considerably within this period. It is therefore better to base the evaluation of the TEMIS UV dose rate (available at $10 \mathrm{~min}$ intervals) on the NILU103 data, which have a better temporal resolution; thus, they suffer much less from changes in atmospheric conditions (like clouds) during one measurement than the Brewer measurements.

\subsubsection{Effective UV doses from NILU-UV irradiances using a neural network model}

A feed-forward function-approximating $\mathrm{NN}$ model (Hornik et al., 1989) was coded using MATLAB's object-oriented scripting language in conjunction with its Neural Network Toolbox (Beale et al., 2012). As inputs, the NN has time series vectors of NILU103 irradiance measurements at 302, $312,320,340$, and $380 \mathrm{~nm}$ together with temporal variables: the SZA, the day of the week (DOW), the day of the year (DOY), and its sinusoidal components $\sin (\mathrm{DOY} \times 2 \pi / T)$ and $\cos (\mathrm{DOY} \times 2 \pi / T)$, where $T$ is the number of days in the year. As outputs, the NN calculates time series for the biological UV products resulting from B086 response-weighted spectra: i.e., erythemal CIE, vitamin D, and DNA-damage effective doses. The rationale behind including temporal variables in the inputs is that geophysical variables very often exhibit periodicity associated with an annual or diurnal cycle and are now commonly incorporated into atmospheric chemistry models (Kolehmainen et al., 2001). From the NILU103 data, a matrix of $n=47908$ co-located input-output vectors was extracted to train and validate the model. All output variables were found to correlate strongly and positively on all five of the irradiances $(0.922 \leq r \leq 0.995)$, strongly 

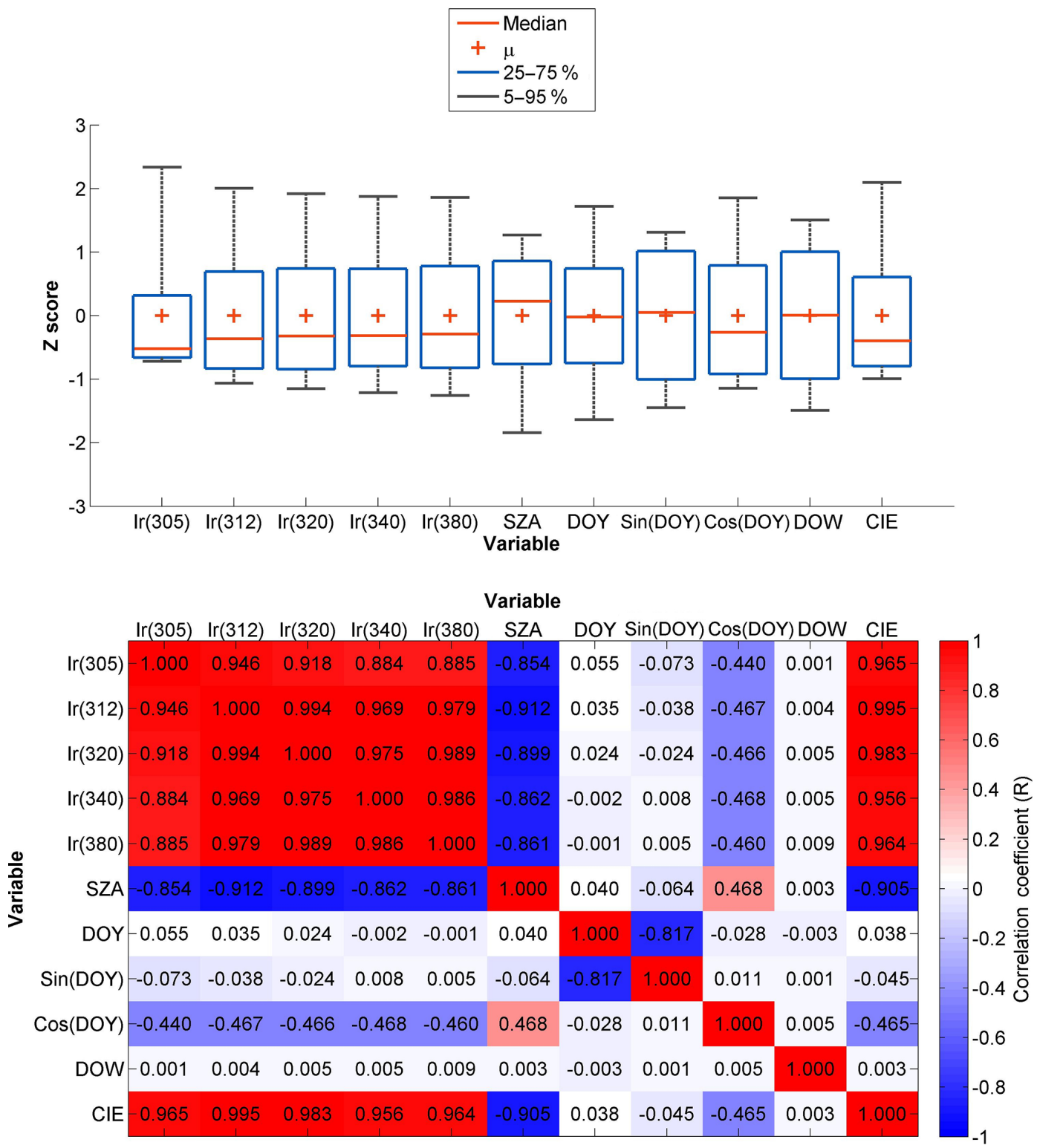

Figure 2. Model selection. Top: boxplots of the $z$ scores of the input variables and the erythemal UV dose (CIE) with mean values denoted by $\mu$. Bottom: the pairwise linear Pearson correlation coefficient for each combination of the input variables and/or the output variable. The results are unnoticeably different in the case of vitamin D and DNA-damage doses. To save space, we have used abbreviated labeling of the sinusoidal terms so that, for example, $\sin (\mathrm{DOY})$ refers explicitly to $\sin (\mathrm{DOY} \times 2 \pi / T)$.

anti-correlate with SZA $(-0.891 \leq r \leq-0.909)$, and weakly anti-correlate with the temporal variables. Figure 2 shows the $z$ scores of the input variables and the erythemal UV dose ("CIE") together with the pairwise linear Pearson correlation coefficient.

The input and output vectors used in our study were connected via two network layers, the first containing hidden neurons with hyperbolic tangent $(\tan h)$ activation functions and the second containing linear activation functions. The mathematical details of this input-output structure is described in Appendix A. Key to the success of the modeling approach is signal-to-noise separation. The NN model is constructed using denoised time series of the NILU-UV irradiances and denoised time series of the photobiological products. Once constructed, the original (noisy) data are input to the model to calculate the photobiological outputs. In order to achieve this, we applied singular spectrum analysis to separate the signal (total trend plus periodicity) from the total noise component for each of the irradiance and photobiological product time series (see Ghil et al., 2002, for a review of the singular spectrum analysis methodology). In this work we calculated the unbiased estimator for the lag-covariance 

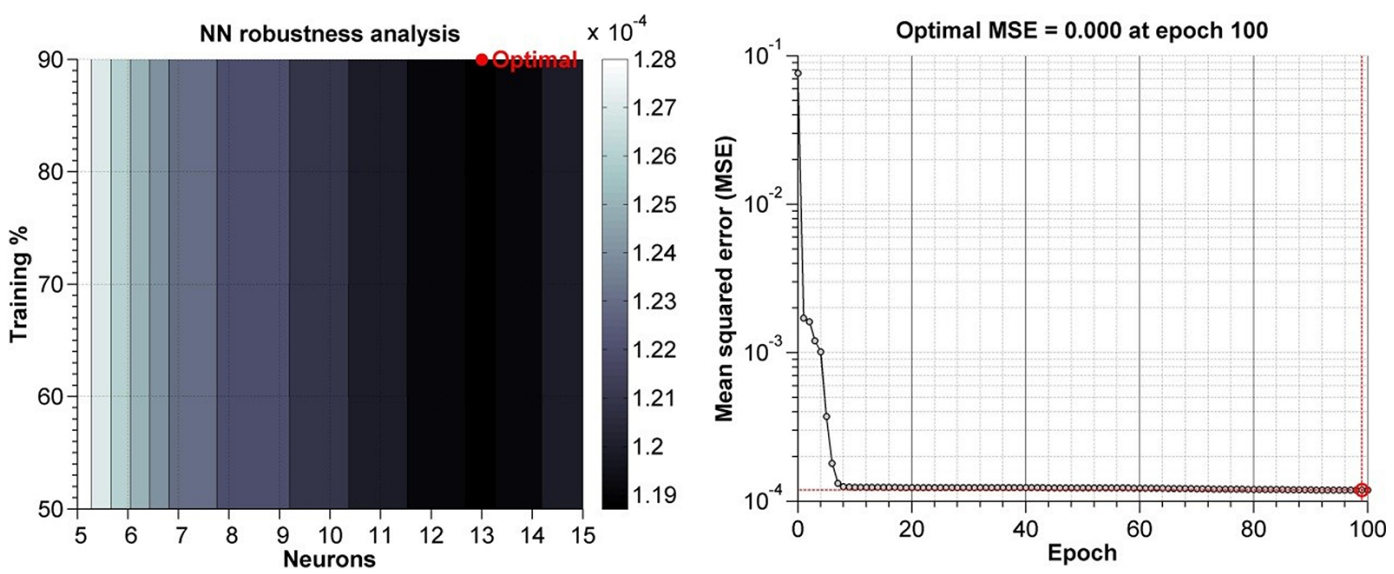

Figure 3. Left: the robustness analysis on the grid of $100 \mathrm{NN}$ models using the minimum validation mean squared error (MSE) as the criterion for selection of the optimal NN architecture (which was found to have 13 hidden neurons and a training: validation data split of $90 \%: 10 \%$ ). Right: the progress of the NN training of the optimal architecture with back-propagation iteration out to 100 iterations "epochs", where $\mathrm{MSE}<1.0 e^{-4}$.

matrix using the method of Vautard et al. (1992). The window length was rounded to $[\log (n)]^{1.5}=36$ following the recommendation of Kahn and Poskitt (2010) and the minimum distance length criterion they introduce was applied. This was found to give a consistent separation of the signal from noise for the NILU103 irradiance measurements at 302, $312,320,340$, and $380 \mathrm{~nm}$ at eigenvalue ranks $9,7,7,5$, and 5 , respectively, and in the case of the photobiological products at eigenvalue ranks 7,8 , and 8 , respectively, for CIE, vitamin D, and DNA. This denoised data structure enables the $\mathrm{NN}$ model to determine the underlying relation between the input and output parameters most efficiently.

The optimal NN architecture was then found by minimizing the mean squared error (MSE) between the NN estimates and Brewer reference output data for each $\mathrm{NN}$ in a grid of $100 \mathrm{NN}$ architectures where the number of hidden neurons was varied from 5 to 15 and the proportion of training data $(t / n)$ was varied from 50 to $95 \%$ in steps of $5 \%$. The subset of $t$ vectors was chosen randomly with a random number generator applied to the vector of indices $[1: n]$ and the remainder being used as a validation set that contained $(n-t)$ vectors. During each of 100 iterations of the learning process, the weights and biases of each NN are tuned with the back-propagation optimization algorithm (Rumelhart et al., 1986) to minimize the MSE cost function over the set of input-output vectors. We have used the Bayesian regularization scheme based on a Laplace prior (Foxall et al., 2002). As a result of this initial robustness analysis, the optimal $\mathrm{NN}$ was found to require 13 hidden neurons and a training to validation ratio of $90 \%: 10 \%$ as seen in Fig. 3, which also shows the result of applying the model selection procedure as well as the progression of training of the optimal NN architecture towards convergence at the horizontal asymptote for the "best" validation MSE after 100 epochs of back-propagation learning using Bayesian regularization.
Table 1. Range of validity of the trained optimal NN as determined by its input parameters (upper list) and output parameters (lower list).

\begin{tabular}{lrrrr}
\hline Parameter & Min & Max & Mean & SD \\
\hline $\operatorname{Ir}(302)$ & 0 & 0.017 & 0.003 & 0.004 \\
$\operatorname{Ir}(312)$ & 0 & 0.229 & 0.064 & 0.055 \\
$\operatorname{Ir}(320)$ & 0 & 0.333 & 0.108 & 0.079 \\
$\operatorname{Ir}(340)$ & 0 & 0.678 & 0.252 & 0.159 \\
$\operatorname{Ir}(380)$ & 0 & 0.871 & 0.327 & 0.208 \\
SZA & 15.63 & 81.162 & 54.373 & 16.120 \\
\hline CIE & 0 & 0.234 & 0.056 & 0.054 \\
Vitamin D & 0 & 0.460 & 0.103 & 0.107 \\
DNA & 0 & 0.011 & 0.002 & 0.002 \\
\hline
\end{tabular}

Note that for the rather long time series used here, there is almost no visual dependence on the training fraction above $50 \%$ with a gradient in the optimization surface only being apparent in the direction of increasing number of neurons.

It is important to note that the optimal $\mathrm{NN}$ is valid for the range of parameters determined by the training data shown in Table 1. Temporal variables other than SZA are not listed and have the following expected ranges: $\mathrm{DOY}=[0,366]$, $\sin (\mathrm{DOY} \times 2 \pi / T)=[-1,1], \cos (\mathrm{DOY} \times 2 \pi / T)=[-1,1]$, and DOW $=[1,7]$.

For validation, this optimally trained $\mathrm{NN}$ was then fed with the remaining "unseen") input vectors from the $10 \%$ of the training data and its estimates are compared against the target measurements of the output vector to evaluate the network performance. The correlation of NILU103 NN estimates with target outputs was high ( $r=0.988$ to 0.990$)$ and found to have a very low bias ( 0.000 to 0.011 absolute units) as shown in Fig. 4. 

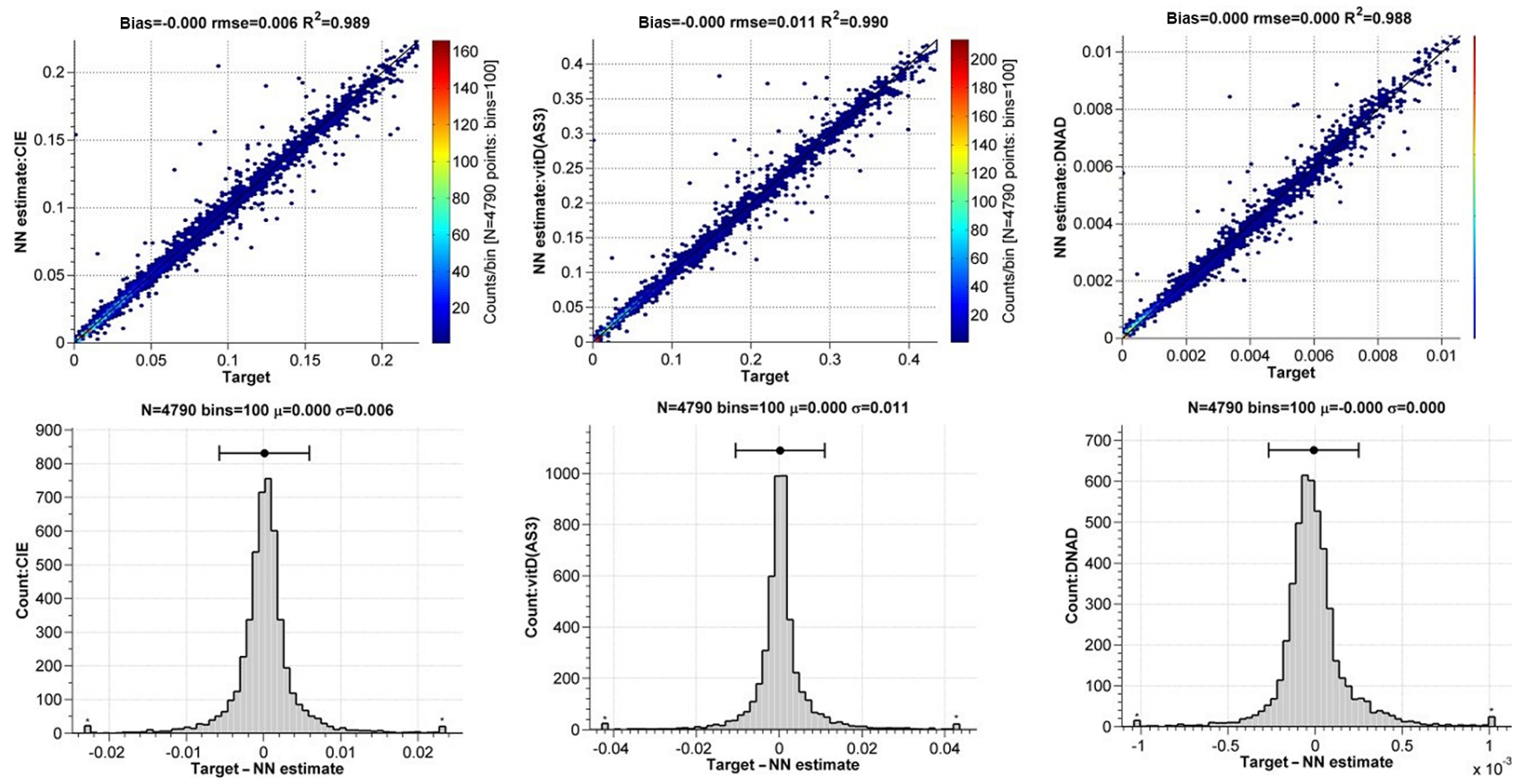

Figure 4. NN validation. Upper panels: regression of the NILU103 NN estimates on the coincident Brewer-derived erythemal UV dose (CIE) (left), vitamin D (center), and DNA-damage dose (right). Lower panels: histograms of the difference between NN estimates and the Brewer-derived quantities. The mean $(\mu)$ and standard deviation $(\sigma)$ are indicated.

Neural-network-based estimates of retrieval uncertainty is still embryonic (see, for example, Ristovski et al., 2012) due to the difficulty associated with propagating errors through a nonlinear function. In order to provide a rough estimate, we calculated the median absolute percentage error (MAPE) for the difference between the target values and the $\mathrm{NN}$ outputs and obtained the following estimates of the NN uncertainty: $\Delta(\mathrm{CIE})=3.6, \Delta($ vitamin $\mathrm{D})=4.5$, and $\Delta(\mathrm{DNA})=5.1 \%$. The uncertainties seen in the NILU NN products are well aligned with the uncertainties introduced by the NILU and B086 irradiances, 5.6 and 5\%, respectively. An estimation of the uncertainty in the NILU NN products based on error propagation results in absolute errors of less than $7.5 \%$ for all three products.

\subsubsection{Effective UV doses from the UVB-1 radiometer}

As described in Sect. 3.1, the measured doses by the YES UVB-1 radiometer are converted to erythemal doses by applying proper correction factors which depend on the values of SZA and TOC for each measurement. The parametrization suggested by Fioletov et al. (2009) is then applied to convert the erythemal dose to vitamin D effective dose. Based on the measurements of B086 we found that when the UV index is lower than 2, the vitamin D is overestimated significantly and should be divided by the following correction factor (cf) obtained empirically by a least squares fit to the data:

$\mathrm{cf}=-0.086 \cdot \mathrm{UVI}^{3}+0.379 \cdot \mathrm{UVI}^{2}-0.575 \cdot \mathrm{UVI}+1.317$
In a similar way, the DNA-damage effective doses were estimated from a more complex empirical relationship that was developed using data from B086 for the period 1993-2010 and evaluated using data for the period 2011-2014. The relationship for the DNA-damage effective doses consists of TOC, CIE, the cosine of the SZA $(\cos \theta)$ and the ratio between the CIE and the climatological value of CIE on each day and $\mathrm{SZA}\left(\mathrm{CIE}_{\mathrm{clim}}\right)$ :

$$
\begin{aligned}
\text { DNA } & =g\left(\mathrm{TOC}, \mathrm{CIE}, \cos \theta, \mathrm{CIE}_{\mathrm{clim}}\right) \\
& =f(\mathrm{CIE}, \mathrm{TOC}) /(\operatorname{cf} 1(\cos \theta) \cdot \operatorname{cf} 2(r)),
\end{aligned}
$$

where

$r=\mathrm{CIE} / \mathrm{CIE}_{\mathrm{clim}}$,

$f$ (CIE, TOC)

$=\left(\frac{a_{1}+a_{2} \cdot \mathrm{CIE}+a_{3} \cdot \mathrm{TOC}+a_{4} \cdot \mathrm{CIE}^{2}+a_{5} \cdot \mathrm{CIE} \cdot \mathrm{TOC}+a_{6} \cdot \mathrm{CIE}^{3}+a_{7} \cdot \mathrm{TOC} \cdot \mathrm{CIE}^{2}}{a_{8} \cdot \mathrm{CIE}^{2}+a_{9} \cdot \mathrm{CIE}+a_{10}}\right)$,

$\operatorname{cf} 1(\cos \theta)=b_{1} \cdot e^{b_{2} \cdot \cos \theta}+b_{3} \cdot e^{b_{4} \cdot \cos \theta}$

$\operatorname{cf} 2(r)=\left\{\begin{array}{ll}1, & r>2 \\ c_{1} \cdot r^{2}+c_{2} \cdot r+c_{3}, & r \leq 2\end{array}\right.$.

The values of the constant terms in Eqs. (9-10) are $a_{1}=-2.703 \times 10^{-5}, a_{2}=0.01245, a_{3}=1.428 \times 10^{-8}, a_{4}=$ $0.1151, a_{5}=-1.736 \times 10^{-5}, a_{6}=-0.1505, a_{7}=-9.527 \times$ $10^{-5}, a_{8}=-3.523, a_{9}=0.9388, a_{10}=0.9611, b_{1}=1.022$, $b_{2}=-3.994, \quad b_{3}=0.7306, \quad b_{4}=0.2755, \quad c_{1}=-0.3026$, $c_{2}=0.8971$, and $c_{3}=0.401$. The empirical rule given by 
Eq. (6) was found to be valid for UVIs greater than 0.5. The daily mean TOC from the single-monochromator B005 was used in the empirical equations and in cases of missing data, daily climatological means derived from the 30 -year record of B005 were used. Using the effective doses from the double monochromator B086, we estimated that the $1 \sigma$ uncertainty in the determination of vitamin D is smaller than $3 \%$ for UVI values greater than 2 and exceeds $10 \%$ for UVIs lower than 1 . The $1 \sigma$ uncertainty in the calculation of the effective dose for the DNA damage is smaller than $7 \%$ for the range of used UVIs (i.e., greater than 0.5). The mean ratio between semi-simultaneous measurements of the clear sky erythemal irradiance from the B086 and the pyranometer $( \pm 1$ min differences between the mean time of the spectral scan and the UVB-1 measurements) for SZAs below $80^{\circ}$ for the period 2004-2014 is $1.00 \pm 0.04$, indicating that the uncertainty in the erythemal irradiance from the pyranometer is similar to that of the Brewer B086.

\subsection{Comparison of the NILU-UV and UVB-1 data products}

Following the appropriate methodologies already discussed in Sect. 3.1 and 3.2, erythemal, vitamin D, and DNA-damage daily doses can be obtained from the NILU103 and an erythemal-like measuring instrument, in this case a UVB-1 radiometer. Even though the UVB-1 data were corrected for the degradation of its absolute response with B086 data, the validity of its measurements as absolute values can be used to evaluate the performance of the NN used to derive all of the biological dose products based on NILU-UV measurements.

In order to have comparative results for the satellite data evaluations, daily doses of all three quantities under investigation were calculated and their agreement was evaluated. For these evaluations both the UVB-1 and the NILU103 1 min data were matched in order to avoid discrepancies due to random time gaps in the original time series. Then, the daily integrals were calculated for both NILU103 and UVB-1 datasets, without any other constrains on the data. The UVB1 erythemal daily doses are underestimated on average by $\sim 2 \%$ when compared to NILU103 retrievals, with a standard deviation of $5.4 \%$. When limiting the data to those during which more than $70 \%$ of the original measurements were classified as cloud-free, the average agreement is close to perfect (average difference of $0.5 \%$ ) with a corresponding standard deviation of $4.2 \%$. This cloud classification criterion, according to which days with more than $70 \%$ abundance of cloud-free measurements are characterized as cloud-free, is used throughout the study, unless stated otherwise. As seen in the lower panel of Fig. 5a, during the winter months UVB-1 tends to underestimate the erythemal daily doses, while during the summer months the opposite behavior is observed.

The daily integrated data for vitamin $\mathrm{D}$ retrievals show that there is a good agreement between the UVB-1 and NILU103 sets. In both subsets, i.e., for all and clear skies, respectively, (a)

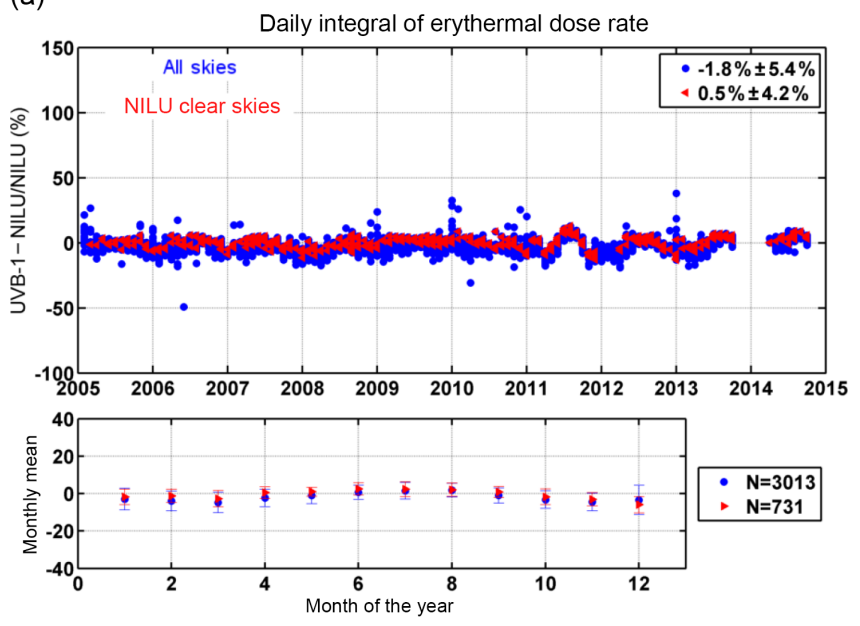

(b)
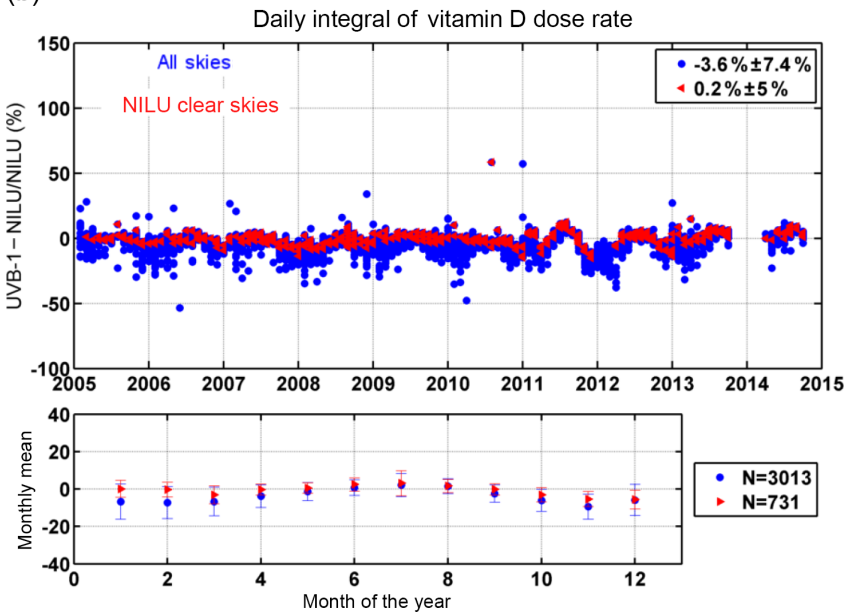

(c)

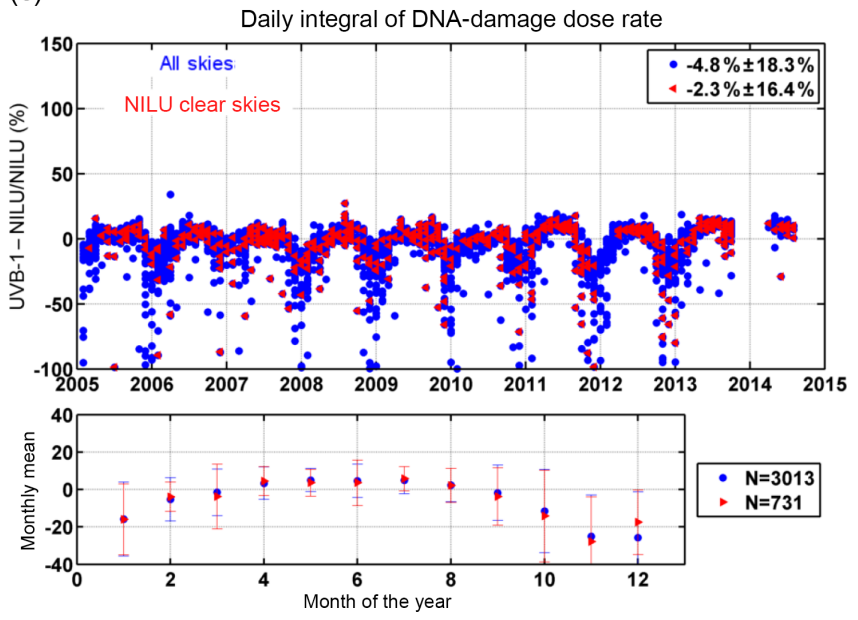

Figure 5. Daily integrals relative percentage differences of erythemal (a), vitamin D (b), and DNA-damage (c) doses estimates from the UVB-1 and NILU103 radiometers (upper panel) and the same datasets averaged on a monthly basis along with the $1 \sigma$ error bars (lower panel). 
the standard deviations of the differences between the two datasets are 7.4 and $5 \%$, respectively, while the differences between the datasets is of the order of $4 \%$ for all skies and approaching zero $(0.2 \%)$ for the cloud-free days only. But, as observed in Fig. 5b, the number of cloud-free days is limited to only $25 \%$ of the originally available amount of days. Again, there is a seasonal pattern for vitamin $\mathrm{D}$ which is similar to the seasonal pattern observed for the daily erythemal doses.

Concerning the DNA-damage daily doses (Fig. 5c), the comparisons show that in general UVB-1 underestimates the daily dose on average by $\sim 5 \%$, with a standard deviation of about $18 \%$. For the cloud-free days, UVB-1 show an underestimation of $\sim 2 \%$ with a standard deviation of about $\sim 16 \%$. The seasonal pattern observed at the lower level of Fig. $5 \mathrm{c}$ is similar to the one depicted for the aforementioned daily doses but enhanced to $\pm 20 \%$, especially for the winter months where the UVB-1 significantly underestimates the doses derived from NILU103, probably due to the fact that the DNA action spectrum peaks at shorter wavelengths.

In Table 2 an analytical overview of the NILU103 and UVB-1 comparison statistics is presented. All three quantities present high $R^{2}$ values (0.99 to 1.00$)$, while the Pearson coefficients $(R)$ reveal a strong linear correlation between the two ground-based datasets with values equal to almost unity. The DNA data are subjected to higher sensitivity in lower wavelengths and exhibit the largest differences between NILU103 and UVB-1.

Generally, the agreement between the two instruments is quite remarkable given the different nature of the original measurements using different spectral resolution and different angular responses, which could be major parameters affecting the comparisons, especially for the seasonal and SZA dependence, while the different retrieval methodologies could lead to further discrepancies.

\section{Evaluation of TEMIS satellite-based UV products with NILU-UV data products}

The satellite-based TEMIS UV products are evaluated for the grid cell containing Thessaloniki (grid cell center: longitude $=22.75^{\circ}$, latitude $=40.75^{\circ}$ ). This evaluation uses a specifically reprocessed dataset (version 1.4) to provide TEMIS UV dose rate values, calculated at the 10 min steps of the time integration of the daily dose UV products which are standard provided to the TEMIS data users. Time series analysis and correlation statistics are performed on the daily UV dose for erythema, vitamin D, and DNA damage over a 6-year period (2009-2014).

As seen in Fig. 6, for all skies the TEMIS UV doses agree within $13 \%$ on average and achieve rather high correlations of $0.92,0.93$, and 0.93 for erythema, vitamin $\mathrm{D}$, and DNA damage, respectively (Fig. 7). The standard deviation of the differences for the three datasets under all skies is 47.3,
45.7 and $47.1 \%$ for erythema, vitamin D, and DNA damage, respectively. The large variations between the satellitebased and ground-based UV daily dose data records can be attributed to different factors. For the full uncertainty, budget contributions relate, for example, to the uncertainty in the B086 originally used spectra, the uncertainty caused by the application of the NILU-UV NN retrieval algorithm, the aerosol climatology assumed in the satellite-based algorithm and total ozone column retrieval errors. However, as will be demonstrated below, the greatest part of the observed spread in the ground-based and satellite-based differences in UV dose is related to the representation of clouds in the satellite algorithm and selection of cloud-free days for the groundbased datasets.

The NILU103 and TEMIS datasets have high coefficients of determination and low biases (small $y$ intercepts) as seen in Fig. 7, while the slopes are close to unity. Although most points seem to cluster evenly around the $y=x$ line especially for the higher values, some overestimation of the satellite products at the lower values results in slopes that are slightly less than unity.

One important aspect for the evaluation is the determination of cloud-free days. The optical geometry of the two monitoring systems is different and the point measurements of the NILU at Thessaloniki compared to the $0.5^{\circ} \times 0.5^{\circ}$ spatial analysis of the satellite-based product may be an important source of discrepancies. Since the satellite-based estimates are based on only one total ozone column value throughout the day, we expect that this could further increase the uncertainty in the satellite-derived daily doses estimates.

Obviously, rapidly changing cloudiness conditions can also lead to large discrepancies between the ground and satellite retrievals. Currently the TEMIS satellite doses over Europe are obtained using the cloud cover fraction per $0.5^{\circ} \times$ $0.5^{\circ}$ grid cell as derived from SEVIRI/Meteosat cloud information (see Sect. 2.2). This information is incorporated in the TEMIS retrieval algorithm on a half-hourly basis, but the frequency of this information might need to be even higher when dealing with high-frequency changing cloudiness conditions as shown in Fig. 8 for two specific cloudy days at Thessaloniki.

The time evolution illustrated for the two days in Fig. 8 show that satellite cloud information cannot capture the rapid changes of cloudiness on these days: the satellite retrievals may either overestimate or underestimate the impact of clouds. Therefore, in order to evaluate the performance of the satellite-based products, the cloudiness effects should be further analyzed. For this, four different cases are examined in more detail: all-sky cases (whose statistical analysis is given in Fig. 6), days with more than $10 \%$ of the measurements characterized as cloud-free (excluding overcast days), days with more than $70 \%$ of the measurements characterized as cloud-free (relatively cloudless days), and days with more than $90 \%$ of the measurements characterized as cloudfree (cloudless days). At this point it should be mentioned 


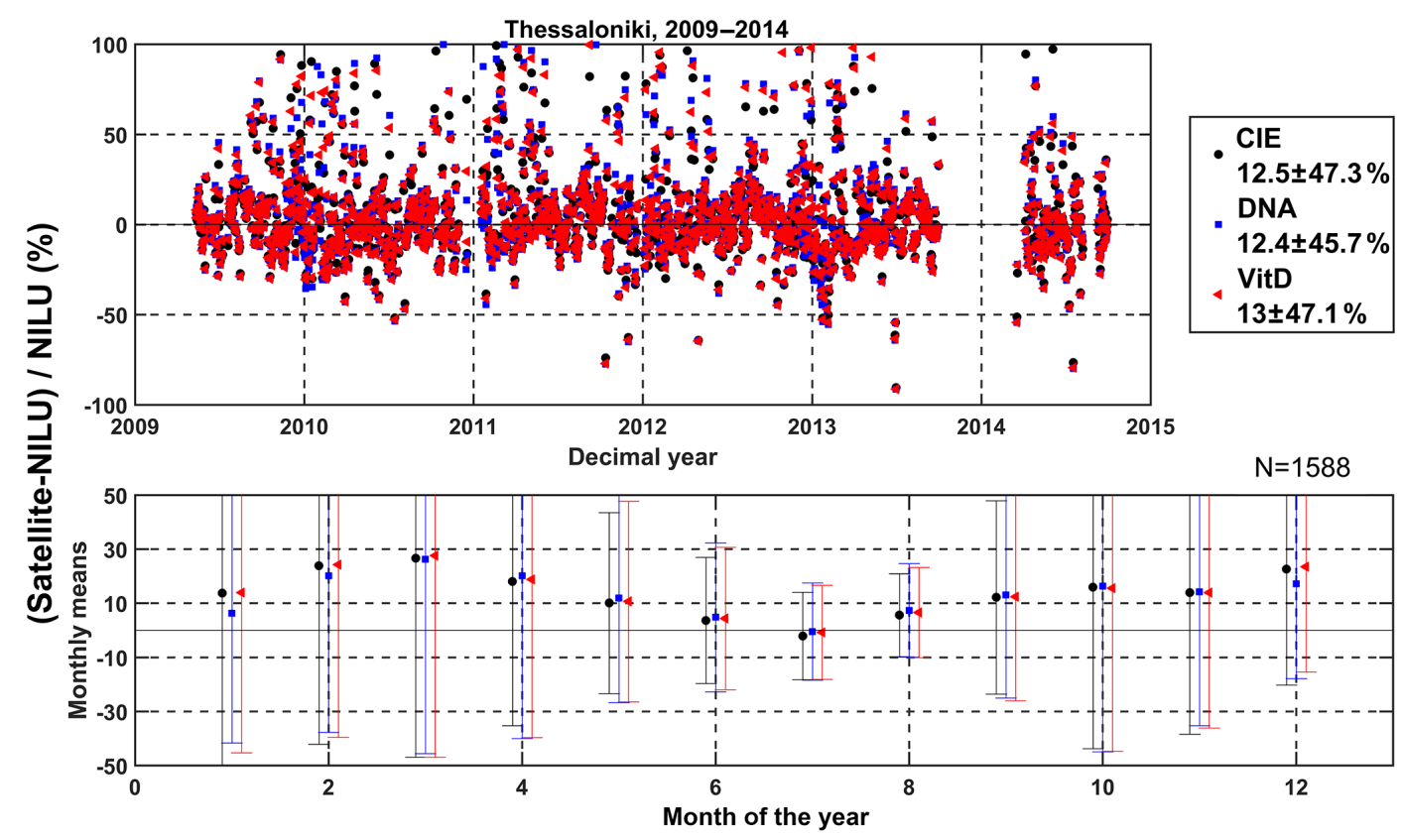

Figure 6. Time series of the relative percentage differences between the SCIAMACHY/GOME2A and NILU-UV effective daily doses under all skies (upper panel) and the seasonality of the differences based on the average month along with the $1 \sigma$ error bars (lower panel).

Table 2. Statistical analysis of the daily integral comparisons between NILU103 and UVB-1 retrievals.

\begin{tabular}{lrrrrrr}
\hline Daily integrals & \multicolumn{2}{c}{ Erythemal $(\%)$} & \multicolumn{2}{c}{ Vitamin D $(\%)$} & \multicolumn{2}{c}{ DNA damage $(\%)$} \\
\hline & All skies & NILU clear & All skies & NILU clear & All skies & NILU clear \\
\hline$N$ counts & 3013 & 731 & 3013 & 731 & 3013 & 731 \\
$R$ & 0.998 & 0.996 & 0.998 & 0.996 & 0.997 & 0.997 \\
$R^{2}$ & 1.00 & 0.99 & 1.00 & 0.99 & 0.99 & 0.99 \\
Mean $(\%)$ & -1.9 & 0.9 & -3.6 & 0.2 & -4.8 & -2.3 \\
SD $(\%)$ & 5.4 & 4.2 & 7.4 & 5.0 & 18.3 & 16.4 \\
\hline
\end{tabular}

that for the characterization of the cloud-free 1 min data, the cloud screening detector proposed by Zempila et al. (2016a) was applied on the NILU103 PAR measurements.

An overview of the impact in limiting the percentage of cloud-free cases per day $(\mathrm{Ncl})$ is provided in Fig. 9 for the erythemal UV doses. The relative percentage differences clearly improve considerably when excluding the overcast days $(\mathrm{Ncl}>10 \%)$. The original $12.5 \%$ average overestimation of the satellite erythemal daily doses is reversed to $1.8 \%$ underestimation, while the standard deviation is less than $15 \%$. When posing the $70 \%$ limitation, as applied on the (UVB-1)-NILU comparisons in Sect. 3.3, the underestimation of the satellite erythemal doses seems to be even less while the standard deviation is similar. However, this limitation is affecting significantly the available number of days fulfilling this restriction through a reduction of number of days by $75 \%$. However, when studying the cloudless days $(\mathrm{Ncl}>90 \%)$, the satellite product is overestimated on average by only $\sim 0.6 \%$ with a corresponding standard deviation of $11.5 \%$. For these cloud-free cases, the interpretation of aerosol effects into the satellite algorithm could be an additional parameter affecting these comparisons (see below).

A comprehensive statistical analysis of all three UV daily doses under investigation for all cloudiness conditions is provided in Table 3. All UV doses, erythemal, vitamin D, and DNA damage, respectively, present high $R^{2}$ values $(\geq 0.9)$ for all the cloudiness restrictions, revealing a high interconnection between the two datasets, while the correlation coefficients denote that under all circumstances, the UV effective doses present a high linear relationship. Although the satellite-based retrievals overestimate for all-sky cases on average by $12.5,13.0$ and $12.4 \%$ for erythemal, vitamin D, and DNA damage respectively (Fig. 6), the percentages are much smaller when considering only cloud-free days (in general less than $1.2 \%$ ). Under mixed cloudiness conditions $(\mathrm{Ncl}>70$ and $>10 \%)$ satellite-based retrievals tend to underestimate the daily doses on average. As seen in Table 3 , 


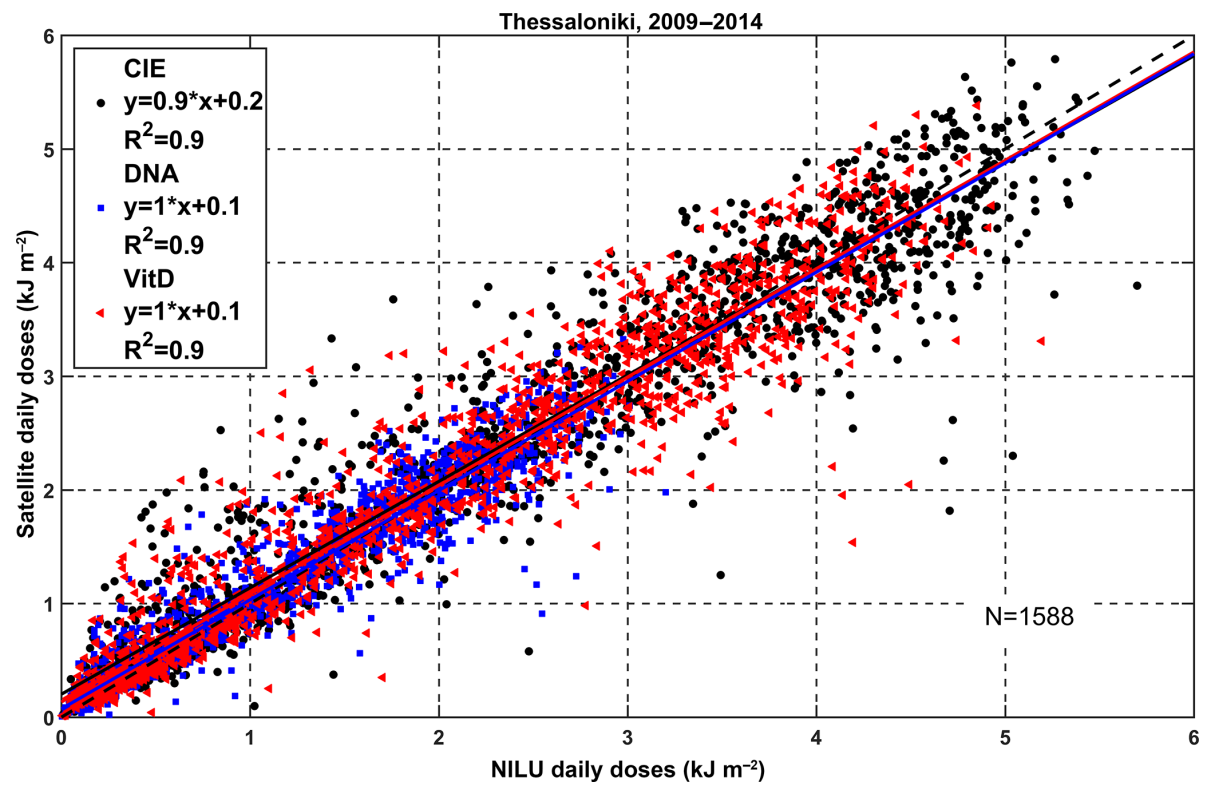

Figure 7. Scatter plot of daily UV dose values provided by the joint SCIA/GOME2A UV products ( $y$ axis) and NILU103 ( $x$ axis) in $\mathrm{kJ} \mathrm{m}^{-2}$ under all-sky conditions.
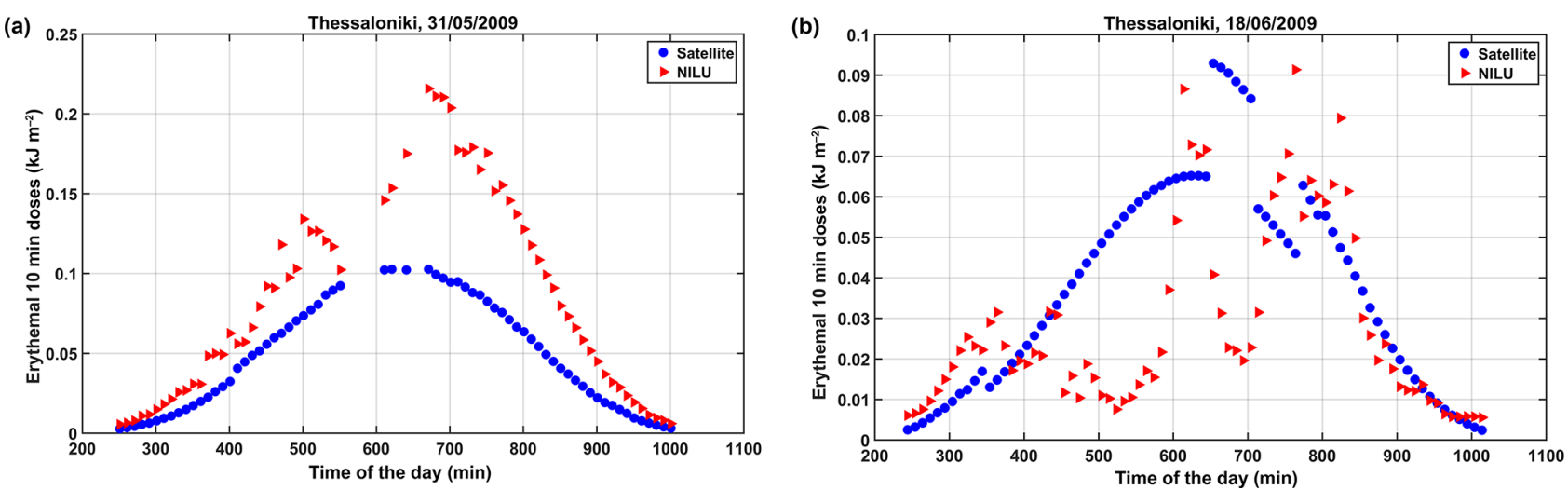

Figure 8. The evolution of the $10 \mathrm{~min}$ erythemal dose over the day as provided by satellite (blue circles) and at the ground (red triangles) for two days in 2009 showing a large temporal variability in cloudiness. The satellite-derived UV daily dose is lower than the NILU103-derived UV dose by $23 \%$ for the case on 30 May 2009 (left panel), while it is larger by $120 \%$ for the case on 18 June 2009 (right panel).

the imposed cloudiness limitations do not alter the standard deviations much.

Table 3 shows that even under cloud-free days there is a scatter of almost $\pm 13 \%$ between the two datasets for all three UV doses. The seasonality seen in Fig. 6 is also present when limiting the datasets to cloud-free days, as seen in the lower panel of Fig. 10, implying that apart from the cloud effects, there are other factors affecting the agreement between the ground- and satellite-based UV data products. One of the causes could be variability in aerosol load over Thessaloniki which is neglected in the satellite-based retrievals.

At Thessaloniki, AOD values at $340 \mathrm{~nm}$ are provided by a CIMEL sun photometer for the period 2011-2014.
In order to investigate the influence of aerosols on the satellite retrievals, estimations of all three UV effective doses every $10 \mathrm{~min}$ were obtained both from the satellite and NILU103 retrieval algorithms. These datasets were limited to periods where the ground-based cloud screening algorithm resulted in cloud-free cases. As seen in the upper level of Fig. 10 there is a strong dependence between the 10 min doses for aerosol optical depth up to 0.4 , while the differences show a slow ascending slope for aerosol loads of more than 0.4. To further attest to this aspect, linear fits were conducted for two datasets, one that comprised data with AOD $\leqslant 0.4$ and the second with data with corresponding AOD $>0.4$. It was found that for all three UV effective doses, the slopes for the first imposed limitation on AOD were 

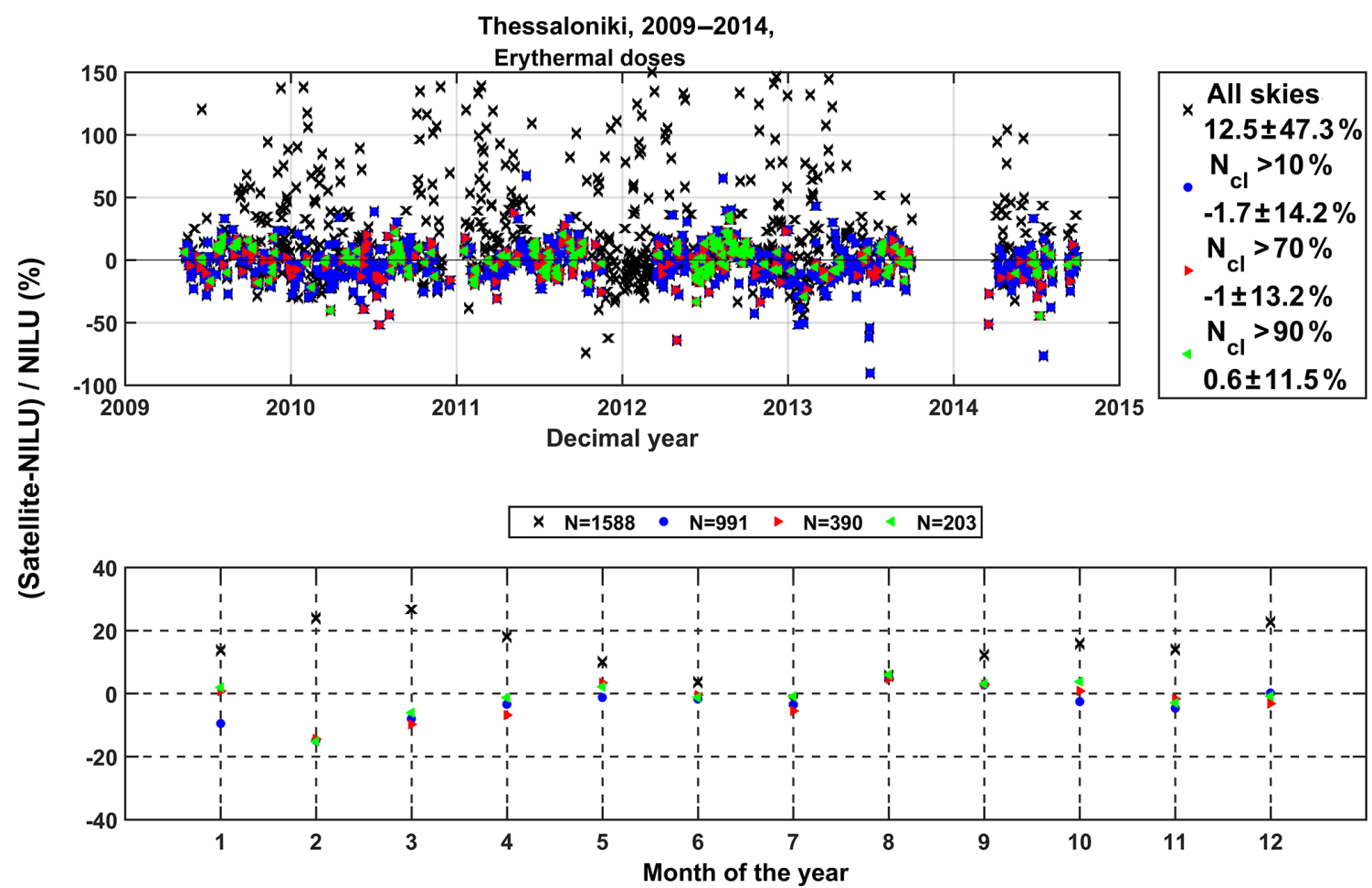

Figure 9. Time series of the relative differences between the satellite-based and ground-based retrieval of the UV erythemal doses; a classification of the cloudless measurements per day is also shown along with the corresponding statistics (upper panel). The seasonality of the data is also presented as monthly mean values (lower panel).

Table 3. Statistical analysis of the relative percentage differences [(satellite - ground)/ground \%] between the satellite and ground estimates based on the cloudless instances within a day; the all-sky values are given in Figs. 6 and 7.

\begin{tabular}{|c|c|c|c|c|c|c|c|c|c|}
\hline \multirow[b]{2}{*}{ Cloudless instances per day $(\%)$} & \multicolumn{3}{|c|}{ Erythemal doses } & \multicolumn{3}{|c|}{ Vitamin D doses } & \multicolumn{3}{|c|}{ DNA-damage doses } \\
\hline & $>90 \%$ & $>70 \%$ & $>10 \%$ & $>90 \%$ & $>70 \%$ & $>10 \%$ & $>90 \%$ & $>70 \%$ & $>10 \%$ \\
\hline$N$ counts & 203 & 390 & 991 & 203 & 390 & 991 & 203 & 390 & 991 \\
\hline$R$ & 0.96 & 0.95 & 0.95 & 0.96 & 0.95 & 0.95 & 0.96 & 0.95 & 0.95 \\
\hline$R^{2}$ & 0.92 & 0.9 & 0.9 & 0.92 & 0.91 & 0.91 & 0.92 & 0.91 & 0.91 \\
\hline Mean $(\%)$ & 0.6 & -1.0 & -1.7 & 1.2 & -0.4 & -1.4 & 1.2 & -0.3 & -1.5 \\
\hline $\mathrm{SD}(\%)$ & 11.5 & 13.2 & 14.2 & 12.9 & 14.5 & 15.2 & 12.2 & 13.9 & 15.8 \\
\hline
\end{tabular}

higher than those calculated for the second dataset. Specifically, the slopes for the two AOD limitations were found to be 44.5 and $11.7 \%$ for the CIE, 50.6 and $8.5 \%$ for the DNA damage, and 46.1 and $8.3 \%$ for the vitamin D doses, respectively. This general pattern is in compliance with the implicit climatological AOD and SSA values applied in the satellite-based retrievals, where the AOD at $368 \mathrm{~nm}$ is assumed to be 0.3 and SSA is set to 0.9 (Sect. 2.2). Arola et al. (2009) used a monthly aerosol climatology for the AOD and SSA at $315 \mathrm{~nm}$ in order to correct the OMI UV irradiances for absorbing aerosols. SSA measurements in UV are not available for the under investigation period in Thessaloniki; thus, a similar study, taking into account the parameter $\tau_{a b s}=\mathrm{AOD} \times(1-\mathrm{SSA})$, cannot be performed.
To further investigate the AOD impact on the comparisons, the monthly means were calculated for both AOD and relative differences. The pattern seen in the monthly means of the AOD values is in general agreement with the seasonality seen in the average monthly values of the relative percentage differences between the satellite- and ground-based $10 \mathrm{~min}$ cloudless doses (Fig. 10, lower panel), implying that there is a link between the two observed seasonalities.

Model estimations performed with the model uvspec of the libRadtran library (v. 1.7) reveal that, for typical aerosol optical properties for the site of Thessaloniki, differences of 0.2 between the AOD values used in the ground-based retrieval algorithm and the measured AOD may be responsible for differences of the order of $10 \%$ between the measured and 

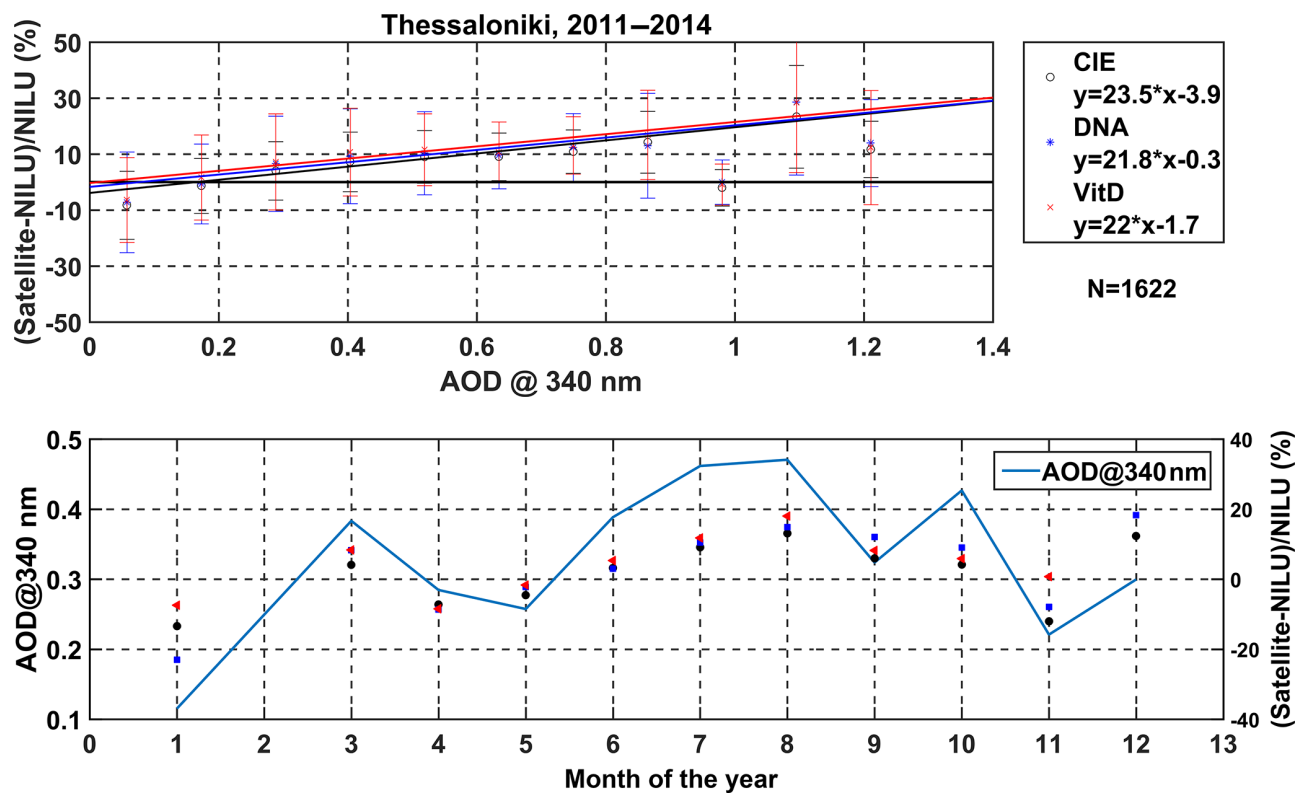

Figure 10. Relative differences of satellite-based and ground-based UV $10 \mathrm{~min}$ doses as a function of AOD at $340 \mathrm{~nm}$ for cloudless cases at Thessaloniki in the period 2011-2014. The statistics are provided in the form of mean and standard deviation of the differences within 11 bins of AOD values. The least squares linear fits for the three doses are also provided (upper panel). Monthly mean values of AOD at $340 \mathrm{~nm}$ along with the mean monthly values of the relative differences presented in the upper panel under cloud-free cases are also provided (lower panel).

retrieved erythemal dose rates. Furthermore, other aerosol properties, like the single-scattering albedo, may vary significantly over urban sites such as Thessaloniki (Bais et al., 2005), which can introduce extra uncertainties in the effect of aerosols on the estimated UV irradiances which are of the same order of magnitude as the uncertainty due to the variability in the AOD (e.g., Kazadzis et al., 2009; Fountoulakis et al., 2016a).

\section{Discussion and conclusions}

In this work a cross-validation between ground-based measurements and evaluation of TEMIS satellite-based estimates has been performed for three important photobiological UV daily dose products: erythemal UV, vitamin $\mathrm{D}$, and DNA damage. The datasets to compare have been produced and compiled such to allow a thorough discussion of their respective accuracies and limitations at the mid-latitude UV and ozone monitoring station in the Laboratory of Atmospheric Physics of the Aristotle University of Thessaloniki, Greece. A neural network (NN) algorithm has been trained on NILU-UV multi-filter radiometer irradiances at five different wavelengths together with weighted action spectra from a Brewer MKIII spectrophotometer to produce $1 \mathrm{~min}$ time series of erythemal UV, vitamin D, and DNA-damage dose rates. Further, the NN estimated erythemal UV dose rates were compared with UVB-1 calibrated UV measurements, and we show how appropriate methodologies can be applied to the original UVB-1 dataset to also produce vitamin D and DNA-damage dose rates at the same temporal resolution as the NILU-UV instrument. In this way we could perform a ground-based verification and evaluation of the developed NN algorithm for the NILU103 measurements. The cross-validation between the NILU103 and the UVB1 dataset revealed a very good agreement. In particular, the following is found:

- The temporally aligned NILU-UV NN and UVB-1 ground-based datasets (30 503 coincident "all-sky" dose rate data records) did not show differences of more than $2 \%$ in their daily integrals and these also had a moderately low standard deviation of $5.4 \%$.

- For vitamin D, the agreement was within $3.6 \%$ for all-sky data with a standard deviation of about $7.4 \%$, largely associated with a SZA dependence at large zenith angles. For cloud-free days this effect is reduced to about $5.0 \%$.

- The DNA dose rates, the most demanding of the three doses discussed in this study because of their sensitivity to short wavelengths in the UV spectral region agree to within about $5 \%$, dropping to $2.3 \%$ for the cloud-free cases.

For the evaluation of the satellite-based TEMIS UV products with the NILU-UV-derived ground-based products, the following, in particular, is found: 
- The TEMIS UV daily dose products are, on average, $12.5 \%$ higher than the NILU103 daily doses under all skies. Despite the presence of a visually apparent seasonal pattern, the correlation was found to be robustly high $\left(R^{2}=0.92\right.$ and $\left.R=0.95\right)$.

- For the vitamin D (DNA damage) UV daily doses the differences under all-sky cases between the satelliteand ground-based estimates are similar with differences of on average $13 \%(12.5 \%)$, again with the satellite overestimating the dose and again with very good correlation of $R^{2}=0.93$ and $R=0.95\left(R^{2}=0.93\right.$ and $R=0.95)$.

It is well possible that the implicit aerosol climatology used in the satellite retrieval algorithm is at least partly contributing to higher UV doses at a moderately polluted site as Thessaloniki. Further, in the shorter wavelength part of the UV-B spectral region errors in measuring the total ozone column can have a relatively higher impact for an accurately retrieval of the DNA-damage UV dose and vitamin D UV dose compared to the erythemal UV dose. However, the ratios and the standard deviations for the differences in the three UV doses are similar, suggesting that the contribution of errors related to the total ozone column retrieval may not be very important. Uncertainties in the B086 spectra and the methodologies used for the calculation of the vitamin D and DNA-damage effective doses might also be partly responsible for the observed variability, but these factors can only explain a small fraction of the total variability in the differences (in general less than $7 \%$ for all-sky conditions).

Through data selections for different cloud cover conditions it was shown that the greatest part of the variability is due to the differences between the cloud cover fraction assumed in the satellite algorithm and the definition of cloudfree cases in the ground-based retrievals because the different field of view between the ground- and satellite-based instruments might lead to discrepancies regarding the cloud influences on the UV daily doses. Three clusters of cloudiness types were investigated in order to evaluate the cloud contribution on the differences between the satellite- and groundbased UV daily doses. The introduced clusters were identified based on the percentage of cloud-free periods over a day: excluding overcast days (days with more than $10 \%$ cloudless measurements), moderate cloud-free days (days with more than $70 \%$ cloudless measurements), and cloudfree days (days more than $90 \%$ cloudless measurements).

- The number of cloud-free days limits the dataset to one fourth of the original, while the mean relative differences are reduced for all daily UV doses. Remaining discrepancies are on average less than $1.3 \%$ for the vitamin D and DNA-damage doses, while the agreement for erythemal UV is on average even smaller $(0.6 \%)$, revealing the notable improvement of the comparisons when excluding the cloudiness effects.
- Differences of less than $2 \%$ with moderate standard deviations $(\sim 15 \%)$ are found when excluding the overcast days, implying that the major source of the high differences observed under all-sky cases can be attributed to the availability and treatment of the cloud information; for example, the satellite algorithm cannot distinguish between thin and thick clouds under overcast conditions

Finally, the influence of aerosol variability was investigated using the UV doses from the cloud-free days only. Coincident AOD values at $340 \mathrm{~nm}$ from a collocated CIMEL sun photometer were used in order to examine the dependence of the observed differences to the aerosol load at the urban site in Thessaloniki. The results showed that for AOD values up to 0.4 the contribution of aerosols to the differences in UV dose is quite significant, while for even larger AOD this contribution results to slowly ascending slops. Furthermore, model estimations demonstrated that discrepancies between the measured and assumed SSA values can also lead to high differences on the retrieved irradiances which are equivalent to those attributed to the variability in AOD. Thus, the discrepancies seen in the two datasets under cloud-free conditions can be at least partly attributed to the implicit aerosol information used in the satellite retrievals at the site of Thessaloniki, which experiences significant variations in aerosol properties.

In conclusion, this comprehensive study has revealed the merits, limitations and accuracy of both ground-based and satellite-based estimates of erythemal UV, vitamin D, and DNA-damage daily doses and underlying dose rates. Although calibration procedures, a priori information and constraints of the methods applied in the original datasets can still limit the accuracy of the calculated photobiological products, these types of data comparisons will remain highly important for the validation of satellite-derived UV doses and to further increase awareness of the harmful effects of overexposure to UV radiation.

Data availability. The data used in this study are available from the following sources:

- TEMIS UV and NILU-UV products: https://doi.org/10.13140/RG.2.2.27094.86082, https: //www.researchgate.net/publication/317465914_TEMIS_ UV_product_validation_in_Thessaloniki_Greece;

- UVB-1 and NILU-UV daily products: https://doi.org/10.13140/RG.2.2.15350.80969, https: //www.researchgate.net/publication/317467800_TEMIS_ UV_validation_in_Thessaloniki_Greece_YES_data. 
Appendix A: Neural network input-output theory

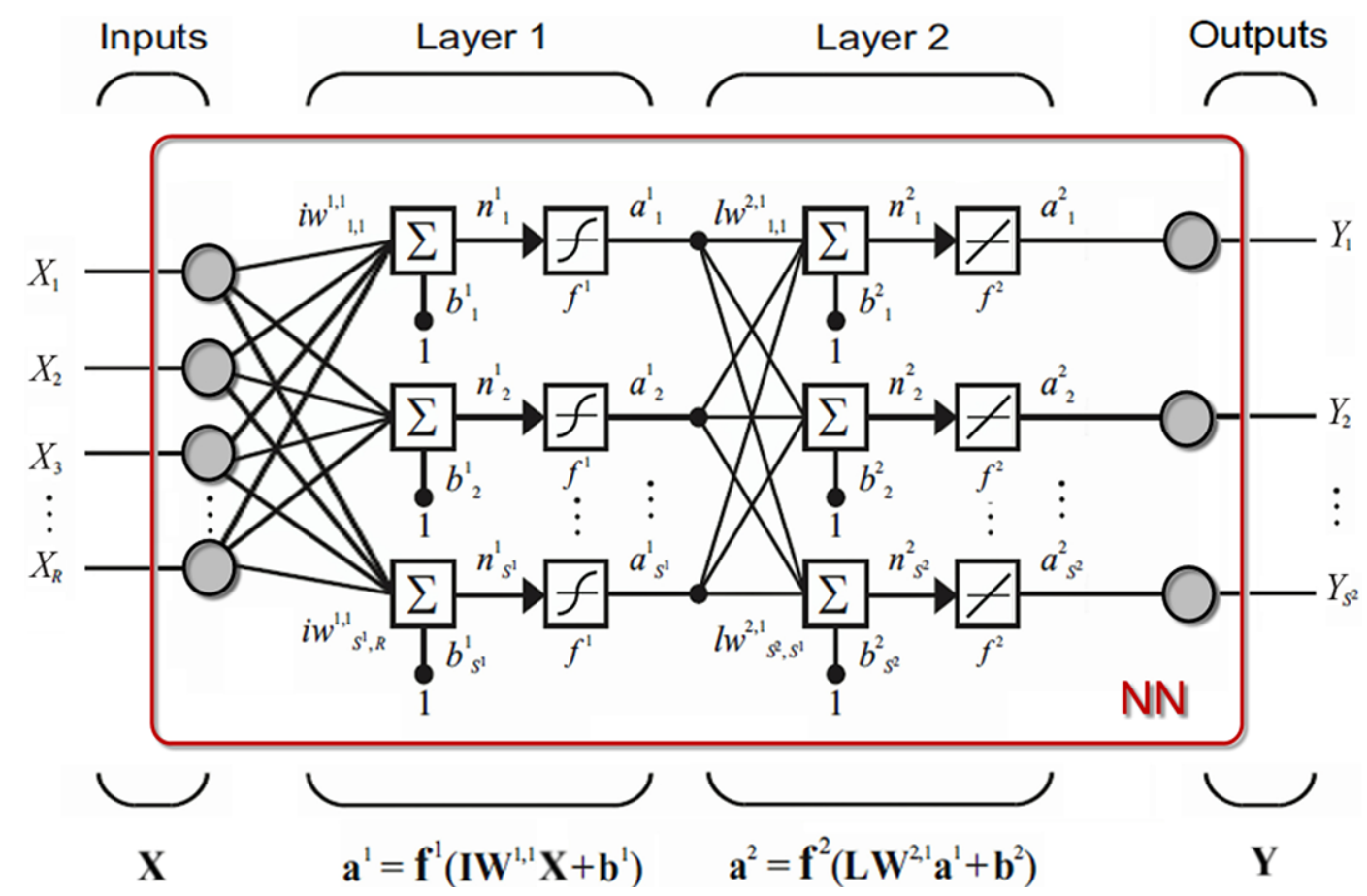

Figure A1. Schematic showing the neural connectivity between input and output parameters in the NILU-UV NN model.

The mathematical structure of the neural network model used in this work is described here and is depicted in Fig. A1.

The NN connects a 10-parameter input vector, $\boldsymbol{X}=[\operatorname{Ir}(302), \operatorname{Ir}(312), \operatorname{Ir}(320), \operatorname{Ir}(340), \operatorname{Ir}(380)$, SZA, DOY, $\sin (\mathrm{DOY} \times 2 \pi / T), \cos (\mathrm{DOY} \times 2 \pi / T), \mathrm{DOW}]^{T}$, through two layers of neurons to a three-parameter output vector $\boldsymbol{Y}=[\mathrm{CIE} \text {, vitamin D, DNA }]^{T}$. Layer 1 (the "hidden" layer) contains $s^{1}=13$ neurons each having a nonlinear activation function $\mathbf{f}^{1}=\tan h$ and Layer 2 (the "output" layer) contains $s^{2}=3$ neurons each having a linear activation function $\mathbf{f}^{2}$. Each neuron also has a single bias $[0,1] . \boldsymbol{a}^{1}$ is the vector of outputs from Layer 1 and $\boldsymbol{a}^{2}$ is the vector of outputs from Layer 2. The vector $\boldsymbol{X}$ is therefore connected to the hidden layer via a matrix of input weights $\mathbf{I W}^{1,1}$ of size $\left[s^{1} \times R\right]$ and the output of the hidden layer is connected to $s^{2}$ output neurons via a matrix of layer weights $\mathbf{L W}^{2,1}$ of size $\left[s^{2} \times s^{1}\right]$. The vector $\boldsymbol{a}^{2}$ for the $s^{2}$-outputs in vector $\boldsymbol{Y}$ is the output of the NN model. The exact mathematical equation relating the outputs to the inputs is represented by the matrix equation (Taylor et al., 2014)

$\boldsymbol{Y}=\mathbf{f}^{2}\left(\mathbf{L} \mathbf{W}^{2,1} \mathbf{f}^{1}\left(\mathbf{I W}^{1,1} \boldsymbol{X}+b^{1}\right)+b^{2}\right)$.

Note that the multiplication of the matrix $\mathbf{I W}^{1,1}$ and the vector $\boldsymbol{X}$ is a dot product and is equivalent to the summation over all input connections to each neuron in the hidden layer. 
Competing interests. The authors declare that they have no conflict of interest.

Acknowledgements. The authors would like to acknowledge the National Network for the Measurement of Ultraviolet Solar Radiation, uvnet.gr. The authors would also like to express their gratitude to Marc Allaart of KNMI for his kind support to the TEMIS algorithm development.

Edited by: S. Kazadzis

Reviewed by: two anonymous referees

\section{References}

Allaart, M., van Weele, M., Fortuin, P., and Kelder, H.: An empirical model to predict the UV-index based on solar zenith angles and total ozone, Meteorol. Appl., 11, 59-65, 2004.

Arola, A., Kazadzis, S., Lindfors, A., et al.: A new approach to correct for absorbing aerosols in OMI UV, Geophys. Res. Lett., 36, L22805, https://doi.org/10.1029/2009GL041137, 2009.

Badosa, J. and van Weele, M.: Effects of aerosols on UV index, Tech. Rep. WR-2002-07, KNMI, De Bilt, 2002.

Bais, A., Zerefos, C., Ziomas, I., Zoumakis, N., Mantis, H., Hofmann, D., and Fiocco, G.: Decreases in the Ozone and the S02 Columns Following the Appearence of the El Chichon Aerosol Cloud at Midlatitude, in: Atmospheric Ozone, Springer, 353356, 1985.

Bais, A. F., Kazantzidis, A., Kazadzis, S., Balis, D. S., Zerefos, C. S., and Meleti, C.: Deriving an effective aerosol single scattering albedo from spectral surface UV irradiance measurements, Atmos. Environ., 39, 1093-1102, 2005.

Balis, D., Giannakaki, E., Müller, D., Amiridis, V., Kelektsoglou, K., Rapsomanikis, S., and Bais, A.: Estimation of the microphysical aerosol properties over Thessaloniki, Greece, during the SCOUT-O3 campaign with the synergy of Raman lidar and Sun photometer data, J. Geophys. Res.-Atmos., 115, D08202, https://doi.org/10.1029/2009JD013088, 2010.

Beale, M. H., Hagan, M. T., and Demuth, H. B.: Neural network toolbox user's guide, in: R2012a, The MathWorks, Inc., 3 Apple Hill Drive Natick, MA 01760-2098, Citeseer, www.mathworks. com (last access: 16 February 2017), 2012.

Bernhard, G. and Seckmeyer, G.: Measurements of spectral solar UV irradiance in tropical Australia, J. Geophys. Res., 102, 87198730, https://doi.org/10.1029/97JD00072, 1997.

Berwick, M., Armstrong, B. K., Ben-Porat, L., Fine, J., Kricker, A., Eberle, C., and Barnhill, R.: Sun exposure and mortality from melanoma, Journal of the National Cancer Institute, 97, 195-199, 2005.

Boersma, K. F., Eskes, H. J., and Brinksma, E. J.: Error analysis for tropospheric $\mathrm{NO}_{2}$ retrieval from space, J. Geophys. Res., 109, 20 pp., https://doi.org/10.1029/2003JD003962, 2004.

Bouillon, R., Eisman, J., Garabedian, M., Holick, M., Kleinschmidt, J., Suda, T., Terenetskaya, I., and Webb, A.: Action spectrum for the production of previtamin D3 in human skin, UDC, 612, 481506, 2006.

Bovensmann, H., Burrows, J. P., Buchwitz, M., Frerick, J., Noel, S., Rozanov, V. V., Chance, K. V., and Goede, A. P. H.:
SCIAMACHY: Mission objectives and measurement modes, J. Atmos. Sci., 56, 127-150, https://doi.org/10.1175/15200469(1999)056<0127:SMOAMM>2.0.CO;2, 1999.

Derrien, M. and Le Gléau, H.: MSG/SEVIRI cloud mask and type from SAFNWC, Int. J. Remote Sens., 26, 4707-4732, https://doi.org/10.1080/01431160500166128, 2005.

Emde, C., Buras-Schnell, R., Kylling, A., Mayer, B., Gasteiger, J., Hamann, U., Kylling, J., Richter, B., Pause, C., Dowling, T., and Bugliaro, L.: The libRadtran software package for radiative transfer calculations (version 2.0.1), Geosci. Model Dev., 9, 1647-1672, https://doi.org/10.5194/gmd-9-1647-2016, 2016.

Engelsen, O., Brustad, M., Aksnes, L., and Lund, E.: Daily duration of vitamin D synthesis in human skin with relation to latitude, total ozone, altitude, ground cover, aerosols and cloud thickness, Photochem. Photobiol., 81, 1287-1290, 2005.

Eskes, H. J., van Velthoven, P. F. J., Valks, P. J. M., and Kelder, H. M.: Assimilation of GOME total ozone satellite observations in a three-dimensional tracer transport model, Q. J. R. Meteorol. Soc., 129, 1663-1681, https://doi.org/10.1256/qj.02.14, 2003.

Fioletov, V. E., McArthur, L. J. B., Mathews, T. W., and Marrett, L.: On the relationship between erythemal and vitamin $\mathrm{D}$ action spectrum weighted ultraviolet radiation, J. Photochem. Photobiol. B, 95, 9-16, 2009.

Fountoulakis, I., Bais, A. F., Fragkos, K., Meleti, C., Tourpali, K., and Zempila, M. M.: Short- and long-term variability of spectral solar UV irradiance at Thessaloniki, Greece: effects of changes in aerosols, total ozone and clouds, Atmos. Chem. Phys., 16, $2493-$ 2505, https://doi.org/10.5194/acp-16-2493-2016, 2016 a.

Fountoulakis, Redondas, Bais, Fountoulakis, I., Redondas, A., Bais, A. F., Rodriguez-Franco, J. J., Fragkos, K., and Cede, A.: Dead time effect on the Brewer measurements: correction and estimated uncertainties, Atmos. Meas. Tech., 9, 1799-1816, https://doi.org/10.5194/amt-9-1799-2016, 2016 b.

Foxall, R. J., Cawley, G. C., Dorling, S. R., and Mandic, D. P.: Error functions for prediction of episodes of poor air quality, in: International Conference on Artificial Neural Networks, Springer, 1031-1036, 2002.

Garane, K., Bais, A. F., Kazadzis, S., Kazantzidis, A., and Meleti, C.: Monitoring of UV spectral irradiance at Thessaloniki (19902005): data re-evaluation and quality control, Ann. Geophys., 24, 3215-3228, https://doi.org/10.5194/angeo-24-3215-2006, 2006.

Ghil, M., Allen, M., Dettinger, M., Ide, K., Kondrashov, D., Mann, M., Robertson, A. W., Saunders, A., Tian, Y., Varadi, F., and Yiou, P.: Advanced spectral methods for climatic time series, Rev. Geophys., 40, 1-41, 2002.

Hassinen, S., Balis, D., Bauer, H., et al.: Overview of the O3M SAF GOME-2 operational atmospheric composition and UV radiation data products and data availability, Atmos. Meas. Tech., 9, 383407, https://doi.org/10.5194/amt-9-383-2016, 2016.

Herman, J. R. and Celarier, E. A.: Earth surface reflectivity climatology at 340-380 nm from TOMS data, J. Geophys. Res., 102, 28003-28011, https://doi.org/10.1029/97JD02074, 1997.

Holick, M., Bouillon, R., Eisman, J., Garabedian, M., Kleinschmidt, J., Suda, T., Terenetskaya, I., and Webb, A.: Action spectrum for production of previtamin D3 in human skin, Tech. Rep. final draft report of September 2005, CIE Technical Committee 6-54, 2005.

Hornik, K., Stinchcombe, M., and White, H.: Multilayer feedforward networks are universal approximators, Neural Networks, 2, 359-366, 1989. 
Kahn, M. A. R. and Poskitt, D. S.: A note on window length selection in singular spectrum analysis, Aust. NZ J. Stat., 55, 87-108, 2013.

Kazadzis, S., Kouremeti, N., Bais, A., Kazantzidis, A., and Meleti, C.: Aerosol forcing efficiency in the UVA region from spectral solar irradiance measurements at an urban environment, Ann. Geophys., 27, 2515-2522, https://doi.org/10.5194/angeo27-2515-2009, 2009.

Kazantzidis, A., Bais, A. F., Topaloglou, C., Garane, K., Zempila, M. M., Meleti, C., and Zerefos, C.: Quality assurance of the Greek UV Network: preliminary results from the pilot phase operation, Proc. SPIE 6362, P. Soc. Photo.-Opt. Ins., 6362, 636229, https://doi.org/10.1117/12.689798, 2006.

Kazantzidis, A., Bais, A. F., Zempila, M. M., Kazadzis, S., Peter, N., Koskela, T., and Slaper, H.: Calculations of the human vitamin D exposure from UV spectral measurements at three European stations, Photoch. Photobio. Sci., 8, 45-51, 2009.

Koelemeijer, R. B. A., De Haan, J. F., and Stammes, P.: A database of spectral surface reflectivity in the range $335-772 \mathrm{~nm}$ derived from 5.5 years of GOME observations, J. Geophys. Res., 108, 4070-4082, https://doi.org/10.1029/2002JD002429, 2003.

Kolehmainen, M., Martikainen, H., and Ruuskanen, J.: Neural networks and periodic components used in air quality forecasting, Atmos. Environ., 35, 815-825, 2001.

Lantz, K. O., Disterhoft, P., DeLuisi, J. J., Early, E., Thompson, A., Bigelow, D., and Slusser, J.: Methodology for deriving clear-sky erythemal calibration factors for UV broadband radiometers of the US Central UV Calibration Facility, J. Atmos. Ocean. Tech., 16, 1736-1752, 1999.

MacLaughlin, J. A., Anderson, R., and Holick, M. F.: Spectral character of sunlight modulates photosynthesis of previtamin D3 and its photoisomers in human skin, Science, 216, 1001-1003, 1982.

McKenzie, R. L., Liley, J. B., and Björn, L. O.: UV radiation: balancing risks and benefits, Photochem. Photobiol., 85, 88-98, 2009.

McKinlay, A. and Diffey, B.: A reference action spectrum for ultraviolet induced erythema in human skin, CIE j, 6, 17-22, 1987.

Meleti, C., Fragkos, K., Bais, A., Tourpali, K., Balis, D., and Zerefos, C.: Thirty years of total ozone measurements at Thessaloniki with a MKII Brewer spectrophotometer, in: Quadrennial Ozone Symposium, 2012.

Parkin, D., Mesher, D., and Sasieni, P.: Cancers attributable to solar (ultraviolet) radiation exposure in the UK in 2010, Brit. J. Cancer, 105, S66-S69, 2011.

Pope, S. J., Holick, M. F., Mackin, S., and Godar, D. E.: Action Spectrum Conversion Factors that Change Erythemally Weighted to Previtamin D3-weighted UV Doses, Photochem. Photobiol., 84, 1277-1283, 2008.

Ristovski, K., Vucetic, S., and Obradovic, Z.: Uncertainty analysis of neural-network-based aerosol retrieval, IEEE T. Geosci. Remote, 50, 409-414,2012.

Rumelhart, D., Hinton, G., and Williams, R.: Learning representations by back-propagation errors, Nature, 323, 533-536, 1986.

Samanek, A. J., Croager, E. J., Gies, P., Milne, E., Prince, R., McMichael, A. J., Lucas, R. M., and Slevin, T.: Estimates of beneficial and harmful sun exposure times during the year for major Australian population centres, Med. J. Australia, 184, 338-341, 2006.
Setlow, R. B.: The wavelengths in sunlight effective in producing skin cancer: a theoretical analysis, P. Natl. Acad. Sci. USA, 71, 3363-3366, 1974.

Slaper, H., Reinen, H., Blumthaler, M., Huber, M., and Kuik, F.: Comparing ground-level spectrally resolved solar UV measurements using various instruments: A technique resolving effects of wavelength shift and slit width, Geophys. Res. Lett., 22, 27212724, 1995.

Taylor, M., Kazadzis, S., Tsekeri, A., Gkikas, A., and Amiridis, V.: Satellite retrieval of aerosol microphysical and optical parameters using neural networks: a new methodology applied to the Sahara desert dust peak, Atmos. Meas. Tech., 7, 3151-3175, https://doi.org/10.5194/amt-7-3151-2014, 2014.

van der A, R. J., Allaart, M. A. F., and Eskes, H. J.: Extended and refined multi sensor reanalysis of total ozone for the period 1970-2012, Atmos. Meas. Tech., 8, 3021-3035, https://doi.org/10.5194/amt-8-3021-2015, 2015.

van Geffen, J., van der A, R., van Weele, M., Allaart, M., and Eskes, H.: Surface UV radiation monitoring based on GOME and SCIAMACHY, in: Proceedings of the ENVISAT \& ERS Symposium, 6-10 September 2004, Salzburg, Austria, SP 572, 8 pp., ESA, Paris, 2004.

van Weele, M., van der A, R. J., van Geffen, J., and Roebeling, R.: Space-based surface UV monitoring for Europe using SCIAMACHY and MSG, in: Proceedings of the 12th SPIE International Symposium on Remote Sensing, 19-22 September 2005, Bruges, Belgium, 8 pp., SPIE, 2005.

Vautard, R., Yiou, P., and Ghil, M.: Singular-spectrum analysis: A toolkit for short, noisy chaotic signals, Physica D, 58, 95-126, 1992.

Webb, A. R. and Engelsen, O.: Calculated ultraviolet exposure levels for a healthy vitamin D status, Photochem. Photobiol., 82, 1697-1703, 2006.

Webb, A. R., Kline, L., and Holick, M. F.: Influence of Season and Latitude on the Cutaneous Synthesis of Vitamin D3: Exposure to Winter Sunlight in Boston and Edmonton Will Not Promote Vitamin D3 Synthesis in Human Skin, J. Clin. Endocr. Metab., 67, 373-378, 1988.

Webb, A. R., Slaper, H., Koepke, P., and Schmalwieser, A. W.: Know Your Standard: Clarifying the CIE Erythema Action Spectrum, Photochem. Photobiol., 87, 483-486, 2011.

Xiang, F., Lucas, R., Hales, S., and Neale, R.: Incidence of nonmelanoma skin cancer in relation to ambient UV radiation in white populations, 1978-2012: empirical relationships, JAMA dermatology, 150, 1063-1071, 2014.

Zempila, M.-M., Giannaros, T. M., Bais, A., Melas, D., and Kazantzidis, A.: Evaluation of WRF shortwave radiation parameterizations in predicting Global Horizontal Irradiance in Greece, Renew. Energ., 86, 831-840, 2016 a.

Zempila, M.-M., Koukouli, M.-E., Bais, A., Fountoulakis, I., Arola, A., Natalia, K., and Balis, D.: OMI/Aura UV product validation using NILU-UV ground-based measurements in Thessaloniki, Greece, Atmos. Environ., 140, 283-297, 2016b.

Zerefos, C.: Evidence of the El Chichón stratospheric volcanic cloud in Northern Greece, Geofis Int., 23, 299-304, 1984. 